\title{
Desafios para prevenção e tratamento do câncer cervicouterino no interior do Nordeste ${ }^{*}$
}

\author{
Noêmia Fernanda Santos Fernandes \\ Patty Fidelis de Almeida ${ }^{\star * *}$ \\ Nília Maria de Brito Lima Prado ${ }^{\star \star \star \star}$ \\ Ângela de Oliveira Carneiro ${ }^{\star \star \star * \star}$ \\ Eduarda Ferreira dos Anjos \\ Jamille Amorim Carvalho Paiva ${ }^{\star \star \star \star \star \star \star}$ \\ Adriano Maia dos Santos ${ }^{\star \star \star \star \star \star \star \star}$
}

Analisa-se a articulação entre Atenção Primária à Saúde (APS) e os diferentes pontos de atenção para controle do câncer do colo do útero (CCU). Trata-se de estudo qualitativo, com dados produzidos em dez grupos focais (70 participantes - enfermeiros e agentes comunitários em saúde) e 12 entrevistas semiestruturadas (seis gestores e seis ginecologistas). Os resultados foram agrupados em três eixos: detecção precoce e controle do CCU na APS; acesso à confirmação diagnóstica; e acesso ao tratamento do CCU e ao transporte sanitário. Os resultados indicam problemas desde o rastreamento (falhas na coleta do Papanicolaou e/ou na leitura das lâminas no laboratório, baixo envolvimento de médicos da APS, ausência de coordenação do cuidado entre níveis) até o tratamento do CCU (barreiras de acesso aos serviços especializados, fragmentação entre os serviços, atraso no tratamento). Entre os achados animadores, destacam-se a prática clínica e o vínculo do enfermeiro com as mulheres durante exame de Papanicolaou e a alta cobertura do exame na APS. Como recomendações apontam-se realização permanente de educação em serviço para ampliar a prática clínica do/a enfermeiro/a e maior envolvimento de médicos, bem como estreitar as relações entre especialistas e profissionais da APS para viabilizar a coordenação do cuidado.

Palavras-chave: Integralidade em saúde. Regionalização. Acesso aos serviços de saúde. Atenção Primária à Saúde. Integração de sistemas. Câncer de colo do útero.

\footnotetext{
* Pesquisa financiada pela Fundação de Amparo à Pesquisa do Estado da Bahia (Fapesb) - Edital n. 08/2015.

** Instituto Multidisciplinar em Saúde, Universidade Federal da Bahia (UFBA), Vitória da Conquista-BA, Brasil (ftanoemiafsf@ gmail.com; https://orcid.org/0000-0002-0713-949X).

*** Instituo de Saúde Coletiva, Universidade Federal Fluminense (UFF), Niterói-RJ, Brasil (pattyfidelis@id.uff.br; https; https://orcid.org/0000-0003-1676-3574).

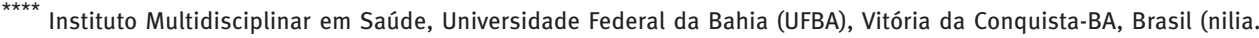
prado@ufba.br; https://orcid.org/0000-0001-8243-5662).

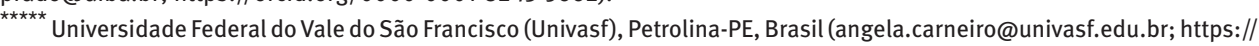
orcid.org/0000-0002-3385-1341).

****** Instituto Multidisciplinar em Saúde, Universidade Federal da Bahia (UFBA), Vitória da Conquista-BA, Brasil (eduardaanjos93@gmail.com; https://orcid.org/0000-0003-4322-236X).

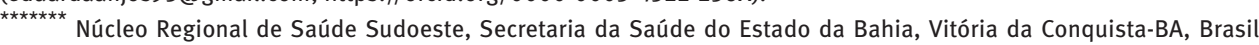
(jmilleamorim@gmail.com; https://orcid.org/0000-0003-2309-4559).

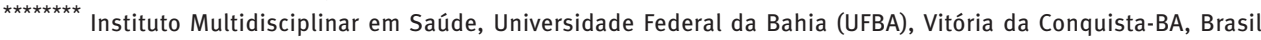
(maiaufba@ufba.br; https://orcid.org/0000-0001-9718-1562).
} 


\section{Introdução}

Entre vários problemas de saúde, o câncer do colo do útero (CCU) é uma das neoplasias com maior incidência em mulheres latino-americanas (GOSS et al., 2013) e uma das principais causas de mortalidade por câncer em mulheres, especialmente em países de baixa e média renda (ARBYN et al. 2020; CANFELL et al., 2020).

No Brasil, os dados de mortalidade de CCU apontam queda na incidência de maneira focalizada, notadamente nas capitais e regiões com maior concentração de renda, devido à ampliação do acesso aos serviços de saúde e melhoria da qualidade do exame citopatológico (BARBOSA et al., 2016; BARCELOS et al., 2017). Tal problemática revela desigualdades não apenas entre os países latino-americanos (SONEJI; FUKUI, 2013; GOSS et al., 2013), mas também internamente num mesmo país (GIRIANELLI; GAMARRA; SILVA, 2014; MALTA; JORGE, 2014), sinalizando a necessidade de investigações que desvelem os territórios do interior do Brasil.

A experiência de alguns países com sistemas de saúde integrados demonstra uma redução de 80\% na incidência do CCU (SONEJI; FUKUI, 2013; ARBYN et al. 2020), quando há uma boa articulação da rede de cuidados e comunicação entre os serviços de saúde e as usuárias, alta cobertura de vacinação contra human papillomavirus (HPV), rastreamento de todas as mulheres na faixa etária preconizada e seguimento de qualidade com tratamento das lesões precursoras (CANFELL et al., 2020; OPAS, 2016).

No cenário do Nordeste brasileiro, altas coberturas de Atenção Primária à Saúde (APS) e oferta regular de rastreamento do CCU não se mostram suficientes para adesão das muIheres aos programas de prevenção (BALDOINO; VERAS, 2016). Nesse sentido, diversos fatores são apontados como obstáculos ao cuidado integral e oportuno: representações socioculturais (BOTTARI; VASCONCELLOS; MENDONÇA, 2008), baixa condição socioeconômica (BARCELOS et al., 2017; BRITO-SILVA et al., 2014), qualidade do rastreamento, bem como o tempo entre diagnóstico e início de tratamento (GALVÃo et al., 2019).

Por outro lado, a existência de equipe multidisciplinar com vínculos de trabalho estáveis (MURAMOTO; MATUMOTO, 2019), atuação vigilante de agentes comunitários de saúde (FERNANDES et al., 2019; TAYLOR et al., 2010), coordenação do cuidado (ALMEIDA; GIOVANELLA, NUNAN, 2012) e adequação da estrutura (MAIA et al., 2011) e do processo de trabalho (TOMASI et al., 2015; COELHO et al., 2009) são características necessárias à qualidade da atenção prestada à saúde da mulher.

Por essa ótica, o cuidado à saúde da mulher (BRASIL, 2016), no âmbito do Sistema Único de Saúde (SUS), especialmente na perspectiva de controle do CCU (BRASIL, 2013; INCA, 2016a; OPAS, 2016), requer integração assistencial de ações e serviços em Redes de Atenção à Saúde (RAS) (MENDES, 2010). Nessa lógica, a RAS seria um arranjo produtivo que combina a concentração territorial de determinados serviços (serviços especializados e hospitalares) e dispersão de outros (Atenção Primária à Saúde - APS), devendo estar 
estruturada a partir da integração horizontal e vertical dos níveis de atenção em territórios sanitários intermunicipais (MENDES, 2010).

Nessa perspectiva, a APS é responsável pela identificação, cadastramento e acompanhamento da população adscrita ao território de suas equipes e, portanto, deve assumir a coordenação do cuidado (STARFIELD, 2002). Além disso, independentemente do local onde as ações e serviços de saúde sejam prestados, a coordenação pela APS sincroniza os cuidados e os voltam ao alcance de um objetivo comum que seja capaz de atender ao conjunto de necessidades dos usuários (ALMEIDA; GIOVANELLA; NUNAN, 2012).

Ademais, o cuidado integral para o controle do CCU (BRITO-SILVA et al., 2014) tem correlação direta com as particularidades do espaço regional (SILVA et al., 2011), a fim de que se alcancem a organização, a gestão e a própria assistência nos diferentes níveis de atenção (BARCELOS et al., 2017; VÁZQUEZ et al., 2017). Entretanto, dificuldades dos usuários em acessar os serviços, maiormente na atenção secundária, vêm acarretando insatisfação e quebra na continuidade do cuidado, revelando um dos entraves para a efetivação da integralidade (GOSS et al., 2013; GALVÃO et al., 2019).

Tais questões estão atadas às evidências de que os governos locais, principalmente em municípios pequenos, possuem pouca capacidade financeira, administrativa e operacional, com consequente dificuldade de descentralização de suas ações (SANTOS, 2018) e, por conseguinte, têm necessidade de compartilhamento de políticas sanitárias em redes regionais de serviços de saúde (ALMEIDA et al., 2019).

De tal modo, este artigo analisa a articulação entre Atenção Primária à Saúde e os diferentes pontos de atenção para controle do câncer cervicouterino em uma região de saúde do Nordeste brasileiro.

\section{Metodologia}

Trata-se de estudo de caso, com abordagem qualitativa (MINAYO, 2014), numa região de saúde na Bahia, Brasil. Uma região de saúde é constituída por agrupamentos de municípios limítrofes, com a finalidade de integrar a organização, o planejamento e a execução de ações e serviços de saúde na perspectiva de garantia da integralidade (BRASIL, 2011).

A região de saúde foi definida por conveniência por ser área de atuação acadêmica dos autores. Além disso, buscou-se dar continuidade a um conjunto de estudos desenvolvidos pelo grupo neste território. Segundo o Instituto Nacional de Câncer (Inca), na Bahia, a incidência estimada de CCU, para 2020, foi de 12,51 casos para cada 100 mil mulheres.

Os 19 municípios que compõem a região de saúde eleita foram agrupados em três estratos por contingente populacional: até 20.000 habitantes; entre 20.001 e 50.000 habitantes; e mais de 50.000 .

Foram eleitos quatro municípios (dos diferentes estratos populacionais) para ilustrar os desafios para prevenção e controle do CCU em uma região de saúde (Tabela 1). 
TABELA 1

Características sociodemográficas e de saúde Região de Saúde de Vitória da Conquista - 2010-2019

\begin{tabular}{|c|c|c|c|c|c|c|c|c|c|}
\hline \multirow{2}{*}{ Localidade } & \multirow{2}{*}{$\begin{array}{l}\text { Distância } \\
\text { à sede } \\
(\mathrm{km})\end{array}$} & \multirow{2}{*}{$\begin{array}{l}\text { População } \\
\text { estimada } \\
(2018)\end{array}$} & \multicolumn{2}{|c|}{$\begin{array}{l}\text { População } \\
\text { (2010) }\end{array}$} & \multirow{2}{*}{$\begin{array}{c}\text { IDHM } \\
(1) \\
(2010)\end{array}$} & \multirow{2}{*}{$\begin{array}{l}\text { População } \\
\text { beneficiada } \\
\text { pelo Bolsa } \\
\text { Família (\%) } \\
\text { (2019) }\end{array}$} & \multirow{2}{*}{$\begin{array}{l}\text { Cobertura } \\
\text { de equipe } \\
\text { de SF (\%) } \\
\text { (2018) }\end{array}$} & \multicolumn{2}{|c|}{$\begin{array}{c}\text { Número de } \\
\text { equipe de SF } \\
(2018)\end{array}$} \\
\hline & & & $\begin{array}{l}\text { Zona } \\
\text { rural }\end{array}$ & $\begin{array}{c}\text { Zona } \\
\text { urbana }\end{array}$ & & & & $\begin{array}{l}\text { Zona } \\
\text { rural }\end{array}$ & $\begin{array}{c}\text { Zona } \\
\text { urbana }\end{array}$ \\
\hline Município A & 130 & 3.577 & 4.221 & 2.817 & 0,538 & 39,2 & 100,0 & 4 & 1 \\
\hline Município B & 31 & 32.018 & 12.381 & 22.407 & 0,551 & 39,4 & 100,0 & 6 & 6 \\
\hline Município C & 69 & 46.862 & 10.042 & 34.659 & 0,604 & 37,6 & 100,0 & 4 & 11 \\
\hline Município D & Sede & 338.885 & 32.127 & 274.739 & 0,678 & 16,9 & 45,0 & 18 & 28 \\
\hline $\begin{array}{l}\text { Região de } \\
\text { Saúde }\end{array}$ & - & 641.560 & 205.475 & 422.309 & - & - & 71,0 & 94 & 83 \\
\hline
\end{tabular}

Fonte: IBGE. Censo Demográfico 2010. Disponível em: https://cidades.ibge.gov.br/. Acesso em: 16 dez. 2019. Ministério da Cidadania. Cadastro Único. Disponível em: aplicacoes.mds.gov.br. Acesso em: 16 dez. 2019. Ministério da Saúde. e-Gestor Atenção Básica. Disponível em: https://egestorab.saude.gov.br/paginas/acessoPublico/relatorios/relHistoricoCobertura.xhtml. Acesso em: 16 dez. 2019. Coordenação de Atenção Básica dos municípios, 2018.

(1) Índice de Desenvolvimento Humano Municipal.

A intenção não foi o julgamento de cada município isoladamente, mas sim a compreensão de processos que acontecem no território regional, por meio de cenários representativos, analisando-se a linha de cuidado para controle do CCU. Os quatro municípios (A, B, C e D) somam mais de $60 \%$ da população da região de saúde, constituindo um corpus (universo estudado) representativo dos fenômenos regionais, pois contém as características essenciais do universo pretendido (MINAYO, 2014).

0 critério de seleção dos municípios se deu pelo cruzamento de informações consideradas relevantes durante a exploração do campo: indicação de informantes-chave; observação em seis reuniões da Comissão Intergestores Regional; cobertura da ESF acima de 90\%; municípios de porte populacional distinto; diferentes tipos de gestão de saúde - em Comando Único e em Gestão Estadual; e inclusão do município-sede da região de saúde - independentemente da cobertura da ESF.

Os resultados emergiram de análises e cruzamentos de dados produzidos por meio de duas técnicas (Quadro 1): dez grupos focais (GF), sendo cinco com enfermeiros (GF-E) e cinco com agentes comunitários de saúde - ACS (GF-A), perfazendo 70 participantes; e 12 entrevistas semiestruturadas, sendo seis gestores e seis médicos ginecologistas.

0 universo empírico dos gestores foi constituído por cinco mulheres e um homem, enquanto o de médicos ginecologistas foi composto por cinco homens e uma mulher. Em relação aos grupos focais, houve apenas um homem (município D) entre todos os enfermeiros participantes. Nos grupos focais de ACS, 32 eram mulheres e apenas cinco eram homens. 


\section{QUADRO 1}

Técnicas de produção de dados e atuação profissional do entrevistado Região de Saúde de Vitória da Conquista - 2017

\begin{tabular}{|c|c|c|c|c|}
\hline Municípios & $\begin{array}{l}\text { Identificação do } \\
\text { grupo focal }\end{array}$ & $\begin{array}{l}\text { Composição dos } \\
\text { grupos }\end{array}$ & $\begin{array}{l}\text { Localidade dos } \\
\text { participantes }\end{array}$ & Tempo \\
\hline \multirow{2}{*}{ Município A } & Grupo I & $\begin{array}{l}7 \text { ACS (mulheres) } \\
3 \text { ACS (homens) }\end{array}$ & Zonas urbana e rural & $2 \mathrm{~h} 35 \mathrm{~min}$ \\
\hline & Grupo II & 5 enfermeiras & Zonas urbana e rural & 2h15min \\
\hline \multirow[t]{2}{*}{ Município B } & Grupo III & $\begin{array}{l}4 \text { ACS (mulheres) } \\
2 \text { ACS (homens) }\end{array}$ & Zonas urbana e rural & $2 \mathrm{~h} 30 \mathrm{~min}$ \\
\hline & Grupo IV & 9 enfermeiras & Zonas urbana e rural & 2h10min \\
\hline \multirow{2}{*}{ Município C } & Grupo V & 7 ACS (mulheres) & Zonas urbana e rural & $2 \mathrm{~h} 35 \mathrm{~min}$ \\
\hline & Grupo VI & 6 enfermeiras & Zonas urbana e rural & $1 \mathrm{~h} 35 \mathrm{~min}$ \\
\hline \multirow{4}{*}{ Município D } & Grupo VII & 8 ACS (mulheres) & Zona urbana & $2 \mathrm{~h}$ \\
\hline & Grupo VIII & 6 ACS (mulheres) & Zonas urbana e rural & $2 \mathrm{~h}$ \\
\hline & Grupo IX & $\begin{array}{l}5 \text { enfermeiras } \\
1 \text { enfermeiro }\end{array}$ & Zona urbana & $2 \mathrm{~h} 15 \mathrm{~min}$ \\
\hline & Grupo X & 7 enfermeiras & Zonas urbana e rural & $2 \mathrm{~h} 15 \mathrm{~min}$ \\
\hline Municípios & $\begin{array}{c}\text { Identificação das } \\
\text { entrevistas }\end{array}$ & \multicolumn{2}{|c|}{ Atuação do entrevistado } & Tempo \\
\hline \multirow{2}{*}{ Município A } & G1 & Gestora & & $46 \min$ \\
\hline & P1 & Médico ginecologista & & $43 \min$ \\
\hline \multirow{5}{*}{ Município B } & G2 & Gestora & & 1h46min \\
\hline & G3 & Gestora & & $2 \mathrm{~h} 17 \mathrm{~min}$ \\
\hline & G4 & Gestor & & $2 \mathrm{~h} 47 \mathrm{~min}$ \\
\hline & G5 & Gestora & & $1 \mathrm{~h} 15 \mathrm{~min}$ \\
\hline & P2 & Médico ginecologista & & $1 \mathrm{~h} 12 \mathrm{~min}$ \\
\hline \multirow{2}{*}{ Município C } & P3 & Médico ginecologista & & $23 \min$ \\
\hline & $\mathrm{P} 4$ & Médico ginecologista & & $28 \mathrm{~min}$ \\
\hline \multirow{3}{*}{ Município D } & P5 & Médica ginecologista & & $4 \mathrm{~h}$ \\
\hline & P6 & Médico ginecologista & & $14 \mathrm{~min}$ \\
\hline & G6 & Gestora & & 2h10min \\
\hline
\end{tabular}

Para composição dos grupos focais, elegeram-se profissionais da ESF com atuação cotidiana na linha de cuidado do CCU. Os critérios de inclusão foram: enfermeiros indicados pelo gestor municipal; ACS apontados pelos enfermeiros selecionados; profissionais (ACS e enfermeiros) de diferentes USF; e profissionais com maior tempo de experiência na ESF.

Realizaram-se dois grupos focais (um com ACS e outro com enfermeiros) por município (A, B e C), mesclando profissionais das zonas rural e urbana. No município D, em decorrência do maior número de equipes, realizaram-se quatro grupos focais, sendo dois com ACS e dois com enfermeiros.

Para seleção dos gestores, elegeram-se aqueles envolvidos na organização dos serviços de saúde com interface com a saúde da mulher em distintos níveis de atenção. Por sua vez, os ginecologistas corresponderam a todos os médicos que atuavam no SUS, em centros de especialidades, e que eram referências na linha de cuidado para controle do CCU em cada município e/ou região de saúde. 
Para análise dos resultados, realizou-se a ordenação dos dados, a partir da leitura geral do material transcrito e primeira organização dos diferentes dados contemplados (grupos focais e entrevistadas semiestruturas). 0 material foi ordenado e classificado, etapas em que as transcrições foram lidas exaustivamente e os núcleos temáticos foram selecionados, agrupados e categorizados. Foram confrontados os argumentos dos grupos focais e das entrevistas semiestruturadas e, em seguida, partiu-se para o cotejamento entre os diferentes discursos, no confronto dialético de ideias e posições dos sujeitos. Para estudo final dos dados, por meio da análise de conteúdo temática, fez-se o entrecruzamento entre as diferentes informações coletadas, identificando-se as convergências e divergências para produção de análise compreensiva e crítica.

A pesquisa foi aprovada pelo Comitê de Ética em Pesquisa da Universidade Federal da Bahia (Parecer n. 624.168), de 24 de abril de 2014. A coleta de dados foi iniciada em julho de 2016 e finalizada em fevereiro de 2017. Todos os participantes da pesquisa assinaram um Termo de Consentimento Livre e Esclarecido.

\section{Resultados}

Os resultados foram agrupados em três eixos temáticos: detecção precoce e controle do CCU na Atenção Primária à Saúde - organização e encaminhamentos; acesso à confirmação diagnóstica - consulta com ginecologista, sistema de apoio diagnóstico/terapêutico e sistema logístico; e acesso ao tratamento do câncer do colo do útero e ao transporte sanitário. Cada eixo temático foi subdividido em categorias temáticas (CT) sinalizadas na descrição dos resultados e nos quadros com os dados empíricos (Quadros 2, 3 e 4), destacando-se os temas que serviram de fio condutor para descrição dos dados.

\section{Eixo I - Detecção precoce e controle do CCU na Atenção Primária à Saúde - organização e encaminhamentos}

Durante a coleta do exame de Papanicolaou, ao detectar alguma alteração ginecológica, os enfermeiros orientavam as mulheres, tratavam quando possível e, havendo necessidade, encaminhavam ao médico da própria unidade ou ao ginecologista da rede. Chamou a atenção, em grupo focal com enfermeiros, a indicação do sistema privado como alternativa para agilizar o resultado e o tratamento de alterações ginecológicas, em decorrência dos tempos de espera alongados no SUS. Porém, os dados revelaram maior resolubilidade da equipe quando os profissionais tinham entrosamento (clínica compartilhada) e, especialmente, quando possuíam formação técnica adequada para lidar com questões clínicas corriqueiras na área da saúde da mulher (CT-1).

Constatou-se a busca pela resolubilidade dos casos clínicos no âmbito da APS, mesmo antes do recebimento do laudo do exame preventivo, revelando a competência dos profissionais em realizar uma clínica ampliada a partir de tecnologias com menor adensamento 
tecnológico e, consequentemente, menor necessidade de encaminhamentos aos serviços especializados e fortalecimento do papel de filtro para outros pontos da rede (CT-1).

Em conformidade com a técnica de coleta durante o preventivo, a lâmina contendo o esfregaço obtido era acondicionada em frasco de vidro esterilizado, juntamente com outras lâminas do dia, embebidas em álcool. Ainda assim, alguns profissionais apontaram descrédito no acondicionamento das lâminas em decorrência da ausência de alguns materiais e da possibilidade de contaminação cruzada entre elas. 0 envio do material coletado à Secretaria Municipal de Saúde era realizado tanto pelas profissionais da APS, quanto por técnicos da Secretaria de Saúde. Esta, por sua vez, disponibilizava um transporte para recolhimento das lâminas nas unidades de saúde. Sobremaneira, quando a unidade de saúde localizava-se na zona urbana, o transporte das lâminas era realizado por técnico da Secretaria de Saúde e, no caso de unidade de saúde de zona rural, o transporte ficava a cargo de algum profissional da equipe, geralmente, o enfermeiro. Em todos os casos, a Secretaria Municipal de Saúde responsabilizava-se por enviar as lâminas ao laboratório (CT-2).

Na sequência, o fluxo de envio das lâminas aos laboratórios de citopatologia e o retorno dos resultados dos exames às unidades de saúde diferiam em cada município. No menor município da região de saúde (município A), o serviço era contratado em laboratório de um município próximo, requerendo o armazenamento de certa quantidade de lâminas até o envio. No município $B$, a leitura das lâminas era realizada no próprio hospital local, por um profissional técnico especializado. No município D (sede da região de saúde), o laboratório era municipal e realizava desde a leitura até o laudo do exame Papanicolaou (CT-2).

Em contrapartida, no município com gestão estadual (município C), as lâminas eram enviadas para o laboratório pactuado pela Secretaria de Saúde do Estado, localizado em Salvador, aproximadamente $450 \mathrm{~km}$ de distância. 0 envio ficava a cargo da Secretaria Municipal de Saúde, necessitando, assim, de acúmulo de lâminas antes do encaminhamento, no sentido de racionalizar o sistema de transporte utilizado (CT-2).

Uma situação que mereceu destaque foi a desconfiança dos enfermeiros sobre os resultados dos exames realizados nas unidades de saúde, pois, muitas vezes, pareciam incompatíveis com a inspeção visual feita no momento da coleta. Todavia, os entrevistados revelaram aspectos relacionados ao acondicionamento das lâminas que podiam comprometer e indicar as razões de ocorrência de laudos de exames citopatológicos falso-negativos e insatisfatórios (CT-3).

Com exceção do município D, nos demais os laudos do exame preventivo eram enviados à Secretaria de Saúde que triava os resultados e os encaminhava às equipes, a fim de verificar a existência de alguma lesão intraepitelial de alto grau (HSIL). De posse dos laudos do exame Papanicolaou, os enfermeiros, caso constatassem alguma lesão precursora, referenciavam a mulher ao ginecologista para realização da colposcopia, bem como os outros procedimentos necessários para confirmação diagnóstica (CT-4). 
Havia diversidade de estratégias para que as mulheres tivessem ciência dos resultados da avaliação oncótica. Algumas equipes faziam busca ativa por meio dos ACS e as mulheres com alguma alteração (HSIL ou LSIL) eram orientadas a irem à unidade de saúde para consulta, a fim de agilizar o seguimento clínico. No caso de lesão intraepitelial de baixo grau (LSIL), as equipes seguiam o protocolo estabelecido pelo Ministério da Saúde e realizavam o acompanhamento dentro da própria unidade de saúde. Entretanto, no município C, todas as mulheres, mesmo com laudo de exame preventivo com LSIL, eram encaminhadas ao ginecologista, divergindo do fluxograma recomendado (CT-4).

Em todo o processo de diagnóstico precoce e rastreamento de controle do CCU, os médicos apareciam apenas no momento em que havia o resultado de HSIL e, raramente, em laudos do exame Papanicolaou com LSIL. Por sua vez, ainda que uma parcela dos enfermeiros percebesse a necessidade de consulta com o médico, enfermeiros sinalizaram a sensação de insegurança quanto à suficiência das orientações fornecidas às usuárias por médicos.

\section{QUADRO 2}

Detecção precoce e controle do CCU na Estratégia Saúde da Família - organização e encaminhamentos

\begin{tabular}{|c|c|}
\hline $\begin{array}{l}\text { Categoria } \\
\text { temática }\end{array}$ & Extratos de falas expressivas \\
\hline \multirow{2}{*}{ 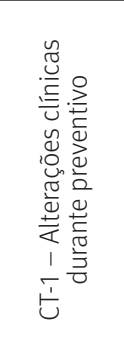 } & $\begin{array}{l}\text { Se tiver necessidade de encaminhamento pra ginecologista, ou quando tá com algum sintoma } \\
\text { importante, encaminho pra avaliação médica do posto ou pro ginecologista [da rede]. E se for } \\
\text { alguma coisa, 'Ah! Tá com leucorreia e algum sintoma, sinais clínicos de candidíase', já encaminho } \\
\text { pro médico [da USF] pra tratar, pois não posso esperar chegar o resultado do preventivo, pra tratar } \\
\text { uma candidíase. (GF-II, Enfermeiros). }\end{array}$ \\
\hline & $\begin{array}{l}\text { A médica [da USF] é gineco-obstetra! Então, no meio do preventivo, qualquer alteração que } \\
\text { visualizo, chamo a médica e já trato naquele momento. As vezes, a médica mesmo resolve, não } \\
\text { precisa nem marcar pro ginecologista [...]. Quando sinto dificuldade, reagendo aquela paciente } \\
\text { [...] No dia que a doutora pode fazer uma consulta compartilhada, aí, ela tira as minhas dúvidas e } \\
\text { vejo se tem alguma alteração [e trato]. Mas se, no momento do preventivo, visualizar algo que não } \\
\text { posso tratar, peço pra paciente procurar um serviço privado, pra que o resultado seja mais rápido e } \\
\text { consiga tratar em tempo hábil (GF-IV, Enfermeiros). }\end{array}$ \\
\hline \multirow{5}{*}{ 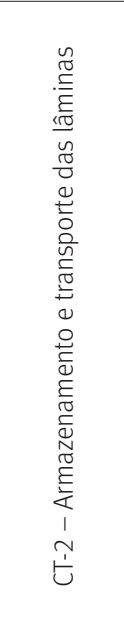 } & $\begin{array}{l}\text { Só não gosto muito de como as lâminas vão pro laboratório [...]. Acho que esse armazenamento, } \\
\text { esse transporte, essa forma toda... Acho que se tivesse aquela divisória, fixador, então, assim, } \\
\text { pelo menos eu ia me sentir mais confiável, mais confortável, em relação a coleta. [...] A gente leva } \\
\text { [lâminas] no isopor [para a secretaria]. Ãs vezes, a gente envia no mesmo dia que coletou e não vai } \\
\text { pro laboratório. Mas aí, quanto tempo [demora], a gente não sabe dizer! (GF-II, Enfermeiros). }\end{array}$ \\
\hline & $\begin{array}{l}\text { É a técnica [no hospital] que fez a capacitação [de preparo das lâminas], quem faz a coloração da } \\
\text { lâmina. Quem lê é a ginecologista. O laudo é impresso na secretaria, a gente pega, assina e leva } \\
\text { pra unidade, na zona rural. Na sede, o carro que leva (GF-IV, Enfermeiros). }\end{array}$ \\
\hline & $\begin{array}{l}\text { Nós realizamos a coleta e essa lâmina ainda vai pra Salvador, pra ser realizada a leitura e retornar } \\
\text { o resultado! Então, demora um pouquinho [...] Quando é rápido, o exame chega em torno de dois } \\
\text { meses, mas já teve casos de chegar em quatro meses [...]. Porque, aqui, funciona o seguinte, faz a } \\
\text { coleta, envia pra secretaria de saúde, aí, às vezes, depende da demanda, da disponibilidade de um } \\
\text { carro que vá pra Salvador pra levar! E os resultados não são on-line (GF-VI, Enfermeiros). }\end{array}$ \\
\hline & $\begin{array}{l}\text { [Carro da secretaria de saúde] passa nas unidades recolhendo o material que a gente coleta para } \\
\text { o laboratório. O pessoal do malote leva para o laboratório [...]. Todos os dias passa na unidade. Se } \\
\text { você fez a coleta na quarta, deixou lá, quinta de manhã ele passou e leva [...] (GF-IX, Enfermeiros). }\end{array}$ \\
\hline & $\begin{array}{l}\text { A lâmina, guardamos no álcool absoluto, não trabalhamos com spray fixador, é com álcool } \\
\text { absoluto! Aí, coloca as lâminas no potinho com clips. A gente pega esse vidrinho, com as lâminas, } \\
\text { identifica, manda junto com o pedido de requisição, os dados; lacra tudo e entrega na secretaria } \\
\text { [...] Na zona rural, a gente traz! (GF-VI, Enfermeiros). }\end{array}$ \\
\hline
\end{tabular}


(Continuação)

\begin{tabular}{|c|c|}
\hline $\begin{array}{l}\text { Categoria } \\
\text { temática }\end{array}$ & Extratos de falas expressivas \\
\hline \multirow{3}{*}{ 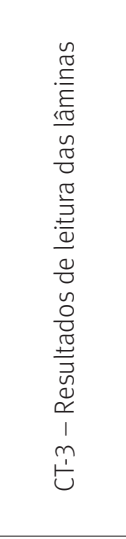 } & $\begin{array}{l}\text { [A necessidade de repetição], na verdade, é mais pela coleta, pois, às vezes, tem piócitos, } \\
\text { resquícios de sangue, então, a gente não sabe se é da coleta ou se é do contato [entre as lâminas]. } \\
\text { Então, tem a forma de armazenamento, de transporte, ressecamento, às vezes, não sei qual é o } \\
\text { motivo, se é por conta do armazenamento [...] às vezes, vem assim, uns casos meio estranhos, } \\
\text { que não tem nada a ver. Porque tudo que a gente vê, a gente anota e, às vezes, não bate! (GF-II, } \\
\text { Enfermeiros). }\end{array}$ \\
\hline & $\begin{array}{l}\text { Aqui faz das duas formas! Quando tem o fixador, a gente usa o fixador! Quando tá em falta, a } \\
\text { gente usa o álcool. Aí, coloca as lâminas, lacra direitinho [...]. A lâmina é identificada, tem a relação } \\
\text { nominal das pacientes e, aí, encaminha para o hospital na sede. Na zona rural, é o motorista } \\
\text { que leva pro hospital [laboratório]. No final da tarde, o carro já faz essa busca [nas USF] (GF-IV, } \\
\text { Enfermeiros). }\end{array}$ \\
\hline & $\begin{array}{l}\text { Nunca presenciei resultado que foi negativo e depois veio com alteração ou alguma lesão, } \\
\text { isso não. Pelo contrário, até dá muito Gardnerella e Trichomonas, que nem é muito o objetivo } \\
\text { principal do preventivo [...] mas vai tudo. Agora inflamação [...] inflamação é 100\%! [...] Sempre dá } \\
\text { inflamaçãa, é recorde! [...] só trato quando tem inflamação, se tiver queixa! [...] Quando chegam } \\
\text { os envelopes [com resultados], olho todos e é muito estranho os resultados; muito parecidos. } \\
\text { Lá na unidade, quando aparece uma paciente alterada é na mesma coleta das outras (GF-X, } \\
\text { Enfermeiros). }\end{array}$ \\
\hline \multirow{4}{*}{ 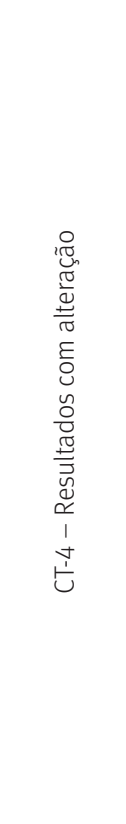 } & $\begin{array}{l}\text { [...] se der alguma alteração a coordenadora entra em contato logo, pelo celular: 'Oh, chegou um } \\
\text { resultado de preventivo que deu alterado. Faça a busca ativa da paciente'! Sinaliza rapidamente } \\
\text { e a gente na unidade, já procura o ACS da área daquela paciente; pro ACS fazer a busca ativa. A } \\
\text { gente ainda fala: 'Oh, chegou o resultado do preventivo, fala pra ela pra ir lá buscar!'. Na minha } \\
\text { unidade, já deixo a consulta com a médica agendada. Ou se ela chegar pra buscar [o resultado] } \\
\text { na unidade, já sinalizo pra doutora. Eu falo: 'Oh, doutora, fulana de tal chegou e tá com o exame } \\
\text { preventivo alterado.' E peço pra entrar logo, pra fazer a consulta (GF-VI, Enfermeiros). }\end{array}$ \\
\hline & $\begin{array}{l}\text { No dia da reunião, a enfermeira ou a doutora pega os resultados e a gente vai pra microárea } \\
\text { e já avisa, ou até mesmo a recepção avisa pra nós. Ou então, já liga e fala: 'Oh, os resultados } \\
\text { chegaram'. E, às vezes, já agenda o dia pra elas virem. Aqueles que têm alteração, que necessitam } \\
\text { urgente de mandar a paciente; [a enfermeira] avisa a gente, pra mandar antes, mais rápido e, aí, } \\
\text { sinaliza nas visitas. Se a visita do mês já foi feita, avisa a paciente e pede para ligar e agendar a } \\
\text { consulta. E já fala se é para o enfermeiro ou médica (GF-l, ACS). }\end{array}$ \\
\hline & $\begin{array}{l}\text { E, aí, então, assim, deu alteração, encaminha pra médica, às vezes, até com a data marcada, a } \\
\text { depender, por exemplo, o mês de junho, que é mais tranquilo, porque o pessoal tá na colheita. } \\
\text { Então, a nossa agenda fica mais livre! Então, essas pessoas já saem agendadas, no dia de retorno } \\
\text { para o médico ou pra mim! Quando tá mais apertada, vou diluindo e priorizando as necessidades. } \\
\text { Mas a maioria dos casos, já dou agendado, porque senão não retornam! Porque se a gente não } \\
\text { mandar pra o ACS entregar [o resultado] já agendado, elas não vão nem buscar! A necessidade } \\
\text { delas é de realizar o exame, agora, o resultado, não importa! Então, quando pega, por exemplo, o } \\
\text { NIC I, essa paciente, automaticamente, jogo pra o primeiro dia, para o médico e já converso com o } \\
\text { médico, antes mesmo da paciente. E já digo que a gente precisa priorizar (GF-IV, Enfermeiros). }\end{array}$ \\
\hline & $\begin{array}{l}\text { No dia da entrega do preventivo, faço um grupo de mulheres, uma vez por mês, aí, junta todos } \\
\text { os resultados. [...] No dia, dou o resultado e explico: 'Olha, o seu resultado deu normal, com esse } \\
\text { resultado você pode ficar até três anos sem fazer. Não deu nenhum problema!'. [As que dão } \\
\text { resultado com alteração] faço atendimento individual. Aí, tenho um turno de Saúde da Mulher, } \\
\text { na quinta-feira, de manhã, que eles [ACS] mandam pra lá, pra o atendimento individual (GF-X, } \\
\text { Enfermeiros). }\end{array}$ \\
\hline
\end{tabular}

\section{Eixo II - Acesso à confirmação diagnóstica - consulta com ginecologista, sistema de apoio diagnóstico/terapêutico e sistema logístico}

0 acesso ao ginecologista, após resultado alterado em exame citopatológico, era o primeiro entrave ao cuidado continuado. No município A, por exemplo, não havia tal especialidade na rede pública local (apenas na rede privada), requerendo a pactuação com a sede da região de saúde que, por sua vez, não conseguia disponibilizar vagas suficientes para todos os municípios via Programação Pactuada e Integrada (PPI). Não por acaso, no município $\mathrm{A}$, as mulheres com alteração citopatológica no exame de Papanicolaou eram 
orientadas, extraoficialmente, para realização de colposcopia e/ou biopsia na rede privada (desembolso direto) ou, quando desprovidas de meios, a Secretaria de Saúde arcava com a compra direta no prestador local (CT-5).

Os municípios B e C possuíam tal especialista na rede local e, nesse aspecto, conseguiam ofertar mais rapidamente a consulta ginecológica de seguimento ao resultado alterado, mas, ainda, com dificuldades para contemplar as necessidades diagnósticas. Por fim, no município D, apesar da oferta desta especialidade, em decorrência da grande demanda local e, também, das demandas oriundas das pactuações intermunicipais, o acesso tornava-se restritivo e/ou delongado, além de comprometer o diagnóstico e tratamento da lesão precursora em tempo oportuno. Por consequência, havia dois desdobramentos corriqueiros: ou a usuária pagava por desembolso direto a consulta com ginecologista (colposcopia e/ou biopsia), ou aguardava a regulação que, frequentemente, aprazava as consultas com tempo acima do preconizado pelo protocolo ministerial (CT-6).

Alguns cenários mostraram-se bastante emblemáticos, uma vez que o município A não oferecia, na rede pública local, nem a consulta ambulatorial com ginecologista, tampouco os procedimentos exigidos para o diagnóstico. Em contrapartida, o município C, apesar de dois ginecologistas na rede própria, necessitava encaminhar as mulheres à sede da região (município D), ou mesmo Salvador $(450 \mathrm{~km})$, para a realização da colposcopia, uma vez que não dispunha do colposcópio no centro ambulatorial de referência, ou seja, tratava-se de estabelecimento simplificado e com baixa resolubilidade para diagnóstico e tratamento de lesões precursoras (CT-6).

$\mathrm{Na}$ região de saúde, a disponibilidade dos ginecologistas dava-se em pequenos ambulatórios de especialidades (municípios B e C) e num centro de saúde tradicional (município D). Nestes locais, os ginecologistas eram referências ao conjunto de unidades de APS e prestavam atendimento mediante encaminhamento das USF ou da central de marcação de consultas (CMC) via regulação assistencial, com responsabilidade em realizar a colposcopia, a biópsia e outros procedimentos para confirmação diagnóstica das lesões precursoras do CCU. Todavia, tratava-se de referenciamento burocrático, pois não havia fluxo comunicacional entre os profissionais da APS e especialistas, bem como, após atendimento ambulatorial, a usuária era responsável pela transferência de informações à equipe, pois não havia contrarreferência.

Não obstante, características socioeconômicas, questões estruturais como dificuldade de transporte entre os municípios - nem sempre disponibilizado pela Secretaria de Saúde -, wnecessidade de desembolso para arcar com alimentação, tempo excessivo entre o deslocamento ao município de referência, a espera pela consulta no estabelecimento (não era por hora marcada) e o retorno à residência incidiam mais gravemente entre mulheres procedentes de zonas rurais (CT-7).

Essas barreiras de acesso contribuem para a iniquidade em saúde, uma vez que parcela da população com maior vulnerabilidade torna-se susceptível a práticas clientelistas para 
garantia de direitos previstos em lei, ou seja, há uma inversão da cidadania em caridade. Não por acaso, foi denunciado acordos entre vereadores e pessoas dos serviços de saúde (algumas vezes coagidos), numa reprodução patrimonialista da coisa pública e troca de favores para manutenção de privilégios (CT-8).

Na região estudada, portanto, constatou-se a dificuldade que os municípios possuem em prover serviços especializados na linha do CCU que atendam à demanda das mulheres do território adstrito. Tal questão dá visibilidade à insuficiência técnica e financeira dos municípios de pequeno porte, que, por outro lado, acabam coaptados à lógica mercadológica e ofertam serviços de maneira segmentada e desarticulados da rede (CT-9).

Outra diferença entre os municípios que merece destaque ocorria na forma de regulação assistencial, uma vez que havia municípios com marcação concentrada na central de marcação de consultas (CMC) e outros com marcação descentralizada nas USF. Naqueles municípios cuja marcação dava-se somente na CMC, o fluxo ocorria com a mulher dirigindo-se com a guia de solicitação de exames diretamente à CMC ou, então, a guia era levada pela própria equipe. Tal modalidade, muitas vezes, transferia à mulher a responsabilidade pela coordenação assistencial e distanciava as equipes das informações acerca dos encaminhamentos para exames complementares (CT-10).

Tanto os profissionais quanto os gestores reconheciam a dificuldade de regulação do acesso aos serviços especializados e, especificamente, quanto ao ginecologista e procedimentos necessários para o cuidado continuado da linha do controle do CCU. 0 preenchimento insuficiente das guias de encaminhamento provocava a necessidade de averiguação da justificativa com as usuárias, em vez de comunicação direta com a equipe de referência do cuidado, expondo o caráter meramente normativo dos fluxos assistenciais (CT-11).

Outro importante problema na linha de cuidado tinha origem no processo de trabalho na APS, essencialmente, no instante de definir critérios para encaminhamento aos demais níveis de atenção. A função de filtro de médicos e enfermeiros era frágil e, por conseguinte, havia encaminhamento ao ginecologista sem o devido critério clínico, em decorrência da pressão das usuárias (consulta "a pedido"). Da mesma maneira, o fluxo comunicacional entre níveis, na rede pública, não lograva contrarreferência à APS das informações provenientes das ações realizadas por ginecologistas, mormente, dos laudos do exame Papanicolaou. Nesse sentido, como era comum que parte das ações, também, fosse realizada no setor privado, a segmentação assistencial amplificava a fragmentação do cuidado. Como consequência, havia insatisfação em todas as direções, porém, com repercussão direta no corpo e na vida das mulheres desassistidas (CT-11).

Essa situação provocava uma fragilização do cuidado continuado e risco ao tratamento da doença instalada, uma vez que a compreensão da usuária sobre fluxo assistencial e termos técnicos era limitada diante das assimetrias de informação e da indefinição de um fluxo compartilhado entre os diferentes pontos (CT-12). 


\section{QUADRO 3}

Acesso à confirmação diagnóstica - consulta com ginecologista, sistema de apoio diagnóstico/ terapêutico e sistema logístico

\begin{tabular}{|c|c|}
\hline $\begin{array}{l}\text { Categoria } \\
\text { temática }\end{array}$ & Extratos de falas expressivas \\
\hline \multirow{4}{*}{ 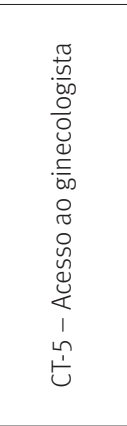 } & $\begin{array}{l}\text { [...] [a mulher] só é encaminhada para o ginecologista depois de algum resultado [alterado]. A maioria } \\
\text { das famílias daqui [recebe] o Bolsa Família. Ficam esperando [a marcação] e quando você [ACS] volta [na } \\
\text { casa] com um ano: 'E o preventivo?' - 'Ah! Não vou fazer não! Você pediu para ir pra o ginecologista e até } \\
\text { hoje não marcou!' [...]. Essa consulta é um pouquinho demorada, porque ginecologista, só [no município } \\
\text { D]! Aqui tem, mas é particular! Pelo SUS, vai jogar na regulação, então, é um pouquinho mais demorado } \\
\text { [...] (GF-I, ACS). }\end{array}$ \\
\hline & $\begin{array}{l}\text { Porque tem pacientes que levam muito tempo pra trazer um resultado [...] E sempre referem: 'Ah! Tem } \\
\text { muito tempo que estou com esse resultado esperando pra ser atendida!' (Ent. P2, Ginecologista). }\end{array}$ \\
\hline & $\begin{array}{l}\text { A demanda do ginecologista é demorada! Quando ela chega no ginecologista, aquele exame, tem tanto tempo } \\
\text { que fez a coleta [...] A ginecologista, o que faz? Ela olha a data e diz: 'Vai fazer de novo!'. [A mulher] volta pra } \\
\text { unidade pra fazer outra coleta. Ela não pode pagar [...] E, aí, vai demorar outro tempo [...] (GF-III, ACS). }\end{array}$ \\
\hline & $\begin{array}{l}\text { Qualquer alteração o médico trata, mas a maioria é encaminhada para o ginecologista, independente da } \\
\text { alteração já encaminha pra o ginecologista pra ter um encaminhamento melhor. [...] são pouquíssimas } \\
\text { vagas. São três vagas no mês com a ginecologista e, aí, vai priorizando (GF-VIII, ACS). }\end{array}$ \\
\hline \multirow{4}{*}{ 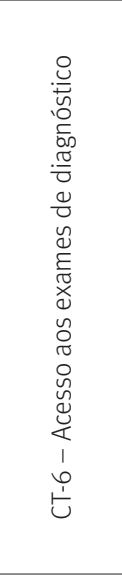 } & $\begin{array}{l}\text { [No caso de colposcopia] encaminha para o município D. Às vezes, a gente consegue vaga e, às vezes, } \\
\text { infelizmente, o próprio paciente paga! [...] A biópsia, a secretaria oferece, manda para o município D, } \\
\text { demora de } 3 \text { a } 4 \text { meses. [Devido à demora] geralmente, [a usuária] acaba pagando (Ent. G1). }\end{array}$ \\
\hline & $\begin{array}{l}\text { Se der alguma alteração, pede a colposcopia [...]. Às vezes, acaba demorando para marcar a colposcopia } \\
\text { e as pacientes acabam fazendo particular. [...] no nosso PSF acontece muito: faz o preventivo; a } \\
\text { enfermeira ou a médica dá o pedido de exame, a colposcopia, por exemplo. Com um ano, [usuária] volta } \\
\text { pra fazer o preventivo, de novo! A enfermeira: - 'Ah! E aquela colposcopia?!'. - 'Ah, não fiz não! Tá lá até } \\
\text { hoje sem marcar!' (GF-I, ACS). }\end{array}$ \\
\hline & $\begin{array}{l}\text { Na minha área demorou [resultado da biópsia]! E, não é o primeiro exame que entrego com gente } \\
\text { falecida, não! Teve um dia que brinquei e falei que 'ia levar lá do outro lado'. E a enfermeira nem gostou } \\
\text { da minha brincadeira. Mas já é o segundo caso! [...] Então, assim, [a usuária] fez tudo [consulta e biópsia], } \\
\text { o material [peça anatômica] ficou em casa com a paciente e nada de conseguir marcar. Enfim, demorou } \\
\text { tanto que a própria ACS pagou pra poder encaminhar! [...] quando chega essa parte da biópsia pra frente; } \\
\text { a barreira é grande! Tem casos que descobre uma suspeita; quando consegue realizar todos os exames, } \\
\text { biópsia, os resultados, a mulher já está fazendo quimioterapia! (GF-III, ACS). }\end{array}$ \\
\hline & $\begin{array}{l}\text { A colposcopia não faz aqui; é no município D! Ou Salvador! [...] Só faz a consulta [com ginecologista]! Aí, } \\
\text { se ele passar a solicitação, se for pra fazer a colposcopia, aî, vem na central [de marcação de consultas] } \\
\text { e marca para o município D! [...] Teve caso, a gente nem chegou a encaminhar pra o ginecologista } \\
\text { [município C]. O resultado deu alterado, passei pro médico da unidade e ele solicitou a colposcopia (GF- } \\
\text { VI, Enfermeiros). }\end{array}$ \\
\hline \multirow{3}{*}{ 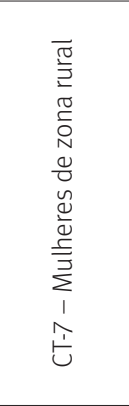 } & $\begin{array}{l}\text { Pacientes da zona rural têm muita dificuldade pra chegar no atendimento [...] porque tem local que é } \\
\text { distante } 50 \mathrm{~km} \text { da zona urbana e fica difícil pra essa paciente chegar pra o atendimento. Então, enquanto as } \\
\text { vagas para zona urbana eram preenchidas, com as [vagas] da zona rural isso não acontecia. [...] Acho que a } \\
\text { principal barreira de acesso é principalmente pra essas mulheres [zona rural], porque daqui que consigam o } \\
\text { atendimento com o ginecologista, pra depois conseguir a biópsia; é muito demorado! (Ent. G4). }\end{array}$ \\
\hline & $\begin{array}{l}\text { [...] a gente [ACS] vê que está demorando muito e já orienta: - 'Vá no particular, adianta a situação, porque } \\
\text { não dá pra esperar muito'. [...] Nós estamos no Outubro Rosa e a gente não tem nada pra oferecer, aí } \\
\text { falam [equipe] para gente: - 'Ah! Vai fazer palestra!'. [...] Então, assim, estamos fazendo esclarecimento, } \\
\text { mas os esclarecimentos, por si só, não tão resolvendo a situação! E a gente fica de pés e mãos atados! } \\
\text { (GF-III, ACS). }\end{array}$ \\
\hline & $\begin{array}{l}\text { [...] quando é uma paciente de zona rural, com pouco entendimento ou se pegou o material [da } \\
\text { biópsia] e não deu o encaminhamento devido [...] [A paciente] volta pra mim, com uma citologia de } \\
\text { novo comprometida [...]. Faço uma nova biópsia, porque aquela pode tá defasada, pode ser que tenha } \\
\text { aumentado o grau [da lesão] (Ent. P2, Ginecologista). }\end{array}$ \\
\hline \multirow{2}{*}{ 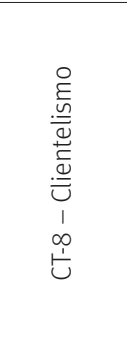 } & $\begin{array}{l}\text { Os municípios, geralmente, têm a pasta dos vereadores! Tem essas pastas de indicação!!! Na nossa gestão } \\
\text { foi abolido isso! Porque o acesso tem que ser igualitário. Inclusive virou um atrito. Eles [vereadores] tinham } \\
\text { acesso direto a central [de marcação], mas foi conversado que não iria marcar em nome de vereador! Só } \\
\text { que a gente sabe que, não a nível do município, mas no geral, o sistema é falho. Que fulano é amigo de } \\
\text { ciclano, que trabalha na regulação ou que trabalha no ambulatório e acaba criando uma facilidade. A gente } \\
\text { sabe que tem essas coisas, então não adianta tapar os olhos, porque tem sim! É é uma coisa que dificulta } \\
\text { muito, porque está tirando a vaga de quem precisa. A gente vê em municípios que até pessoas de alto } \\
\text { escalão conseguem as consultas, tirando de quem precisa (Ent. G3). }\end{array}$ \\
\hline & $\begin{array}{l}\text { A definição da prioridade é o resultado do exame! [...] Mas tem o 'jeitinho', porque tem a vaga do político, } \\
\text { tem a vaga do amigo do amigo, tem a vaga do primo, a vaga do enfermeiro [...]. Trabalho em uma área } \\
\text { extremamente pobre! [...] Quando a pessoa tem que fazer algum exame particular, sei que, no final do } \\
\text { mês, vai ficar sem comer alguma coisa (GF-IV, Enfermeiros). }\end{array}$ \\
\hline
\end{tabular}




\begin{tabular}{|c|c|}
\hline $\begin{array}{l}\text { Categoria } \\
\text { temática }\end{array}$ & Extratos de falas expressivas \\
\hline 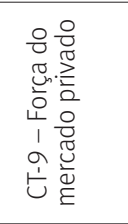 & $\begin{array}{l}\text { O que a gente tentou definir, na Comissão Regional e, que mesmo assim, não está acontecendo do } \\
\text { jeito que foi acordado, foi o fluxo de oncologia! A gente tratou de uma forma mas, até hoje, a gente tem } \\
\text { uma dificuldade muito grande no diagnóstico! O paciente de oncologia, depois que é diagnosticado, } \\
\text { não tem problema! Mas até o diagnóstico, cada município se vira, com o seu paciente! Com biópsia, } \\
\text { com tomografia, o que for precisar! [...] Como é o município D que executa, ela [cidade] abriu o } \\
\text { credenciamento e os profissionais não credenciaram! Então, assim, não podia fechar a pactuação, se } \\
\text { não tinha profissional! [demorou por causa da] tabela SUS! Aí, ficou aberta [a pactuação] quase uns cinco } \\
\text { meses! (Ent. G2). }\end{array}$ \\
\hline \multirow{3}{*}{ 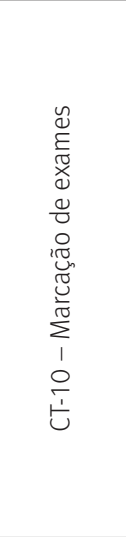 } & $\begin{array}{l}\text { Preencho [guia de solicitação de exames] e mando a paciente procurar direto a central. Porque a } \\
\text { paciente, ao invés de ficar batendo na nossa porta, vai direto ter a resposta! [...] Zona rural, não! Fico } \\
\text { com o exame e venho entregar [na CMC]! [...] Como o meu lugar [ESF] é um local de bastante dificuldade } \\
\text { financeira, então, questiono pra paciente: 'Olha, tem esses exames, que posso deixar na marcação, porém, } \\
\text { não garanto que vai ser marcado pra logo!'. Aí falo: ‘Se tiver condição de fazer particular, faça', mas } \\
\text { dou, também, a opção de deixar na marcação. Não posso induzir, pedir pra ele fazer particular. (GF-II, } \\
\text { Enfermeiros). }\end{array}$ \\
\hline & $\begin{array}{l}\text { A usuária deixa a solicitação com a enfermeira e ela que faz essa marcação por meio da pasta que vem } \\
\text { pra aqui [CMC] na sexta. E aí, se tiver alguma informação específica, a gente também envia. [...] São } \\
\text { quatro vagas, duas pra cada ginecologista. E aí, quando chega aqui, a gente distribui igual entre as } \\
\text { unidades e deixa uma reserva pra as emergências (Ent. G4). }\end{array}$ \\
\hline & $\begin{array}{l}\text { A gente [USF] é descentralizada; marca na própria unidade e é rápido! Como tenho marcador, saio } \\
\text { da sala, vou lá [SAME], marco e volto com o pedido marcado e entrego pra paciente. É muito rápido! } \\
\text { Pra ginecologia [consulta] são três vagas, aí olha, prioriza e agenda, mas colposcopia é livre! Lá no } \\
\text { sistema não aparece vaga [para marcação de colposcopia]. A gente entra em contato direto com o } \\
\text { estabelecimento de saúde [público] por telefone. [...] se [a mulher] foi detectada com lesão de alto } \\
\text { grau, já passa com profissional especializado e a partir daí, é encaminhada pra o que for necessário e } \\
\text { essas marcações já não são mais responsabilidade da unidade. Já são responsabilidade da central de } \\
\text { marcação, que sempre prioriza esses casos (GF-X, Enfermeiros). }\end{array}$ \\
\hline \multirow{5}{*}{ 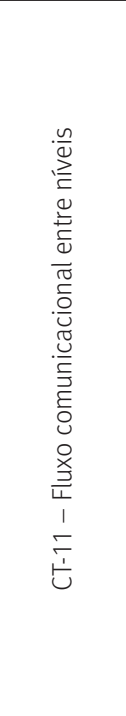 } & $\begin{array}{l}\text { A comunicação é o paciente que vem e que fala! Faço parte do Conselho de Saúde e, há um tempo, } \\
\text { houve esse tipo de questionamento, que de lá, eles não [contrarreferenciam]. Geralmente, a USF não tem } \\
\text { esse retorno, essa comunicação. Então, é a paciente que faz esse retorno pra unidade! [...] E, às vezes, } \\
\text { nem a paciente faz isso! (GF-I, ACS). }\end{array}$ \\
\hline & $\begin{array}{l}\text { Tem médico e enfermeiro que encaminham [a referência]. E, pelo que olho, assim, pelo pedido, da } \\
\text { solicitação, tem mais enfermeiro [...] Vem só a guia: “Consulta ginecológica”, não vem a descrição”! [...] } \\
\text { A relação, às vezes, é com o colega que manda os pacientes, enfermeiro, mas a relação, assim, não é } \\
\text { frequente [...] Acho que poderia ter mais um feedback do enfermeiro pra o médico [...] uma relação maior. } \\
\text { [...] (Ent. P3, Ginecologista). }\end{array}$ \\
\hline & $\begin{array}{l}\text { A APS referencia pra mim! Não tenho nenhum contato com o profissional da APS! Não tenho contato } \\
\text { com nenhum serviço! A ligação que tenho com qualquer outra coisa é a coordenadora do ambulatório. } \\
\text { Então se resolve no ambulatório mesmo, com a usuária [...]. De modo geral, as dúvidas são tiradas com o } \\
\text { encaminhamento das pacientes, às vezes, vem com aquela solicitação de retorno [...]. Eu mando assim: } \\
\text { 'controle, lesão de baixo grau, com x tempo'. Isso aqui já é suficiente pra saber o que a paciente tem que } \\
\text { fazer! (Ent. P2, Ginecologista). }\end{array}$ \\
\hline & $\begin{array}{l}\text { [...] o que percebo de muitas pacientes é que, quando veem, já começam a resolver o seu problema direto na } \\
\text { central, já não retornam mais com tanta facilidade pra a gente, mesmo que a gente faça a busca ativa. Elas } \\
\text { conseguem se resolver na rede! [...] Contrarreferência é um problema! Só recebo do ginecologista na própria } \\
\text { colposcopia, no próprio pedido, mas oficializado, no papel da referência, não! É mais um aviso, recomendação } \\
\text { ou orientação. É mais dizendo o que a usuária tem que fazer, do que dizer pra gente o que eles fizeram, e isso } \\
\text { quando eles não criticam a gente pra a usuária! (GF-X, Enfermeiros). }\end{array}$ \\
\hline & $\begin{array}{l}\text { Quem dá a contrarreferência é o ACS. Elas [mulheres] passam pra gente o que aconteceu e a gente passa } \\
\text { pra equipe. Isso dificulta e muito, porque às vezes está em um tratamento, fazendo radio, quimio e não } \\
\text { sabe o que está fazendo. Aí, a gente tem que procurar quem está acompanhado ela nesse tratamento } \\
\text { (GF-IX, Enfermeiros). }\end{array}$ \\
\hline \multirow{2}{*}{ 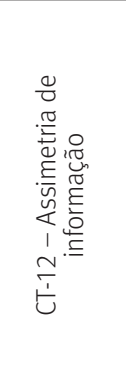 } & $\begin{array}{l}\text { As pacientes chegam aqui totalmente desinformadas, a maioria das vezes, não têm noção. Tanto que a } \\
\text { gente tenta criar na equipe essa questão de orientar a paciente! Chega sem saber pra onde vai; já rondou } \\
\text { em vários lugares, antes de chegar aqui [...] E aí, a gente orienta tudo; os exames que faz aqui, os que } \\
\text { marcam na central [...]. Porque chegam aqui com muita dificuldade! [...] Essa falta de articulação é uma } \\
\text { dificuldade de vários setores, não só é só na oncologia; a gente percebe em outras áreas! [...] A gente já } \\
\text { discutiu com a secretaria sobre a necessidade de se montar esse fluxo, porque, às vezes, a gente recebe } \\
\text { ligação de profissional da APS pedindo orientação de como encaminhar pra o serviço (Ent. G6). }\end{array}$ \\
\hline & $\begin{array}{l}\text { Muitas pacientes chegam aqui em estágio avançado, acredito que pelo desconhecimento da patologia } \\
\text { [..... Algumas chegam aqui sabendo da sua situação, mas óbvio que com um conhecimento mais } \\
\text { superficial. Então, assim, geralmente não sabem detalhes de como vai ser o tratamento [...]. É mais um } \\
\text { ou outro paciente, que é mais idoso e a família não quer contar [...] Âs vezes, tem paciente que chega } \\
\text { aqui com uma biópsia de } 1 \text { ano, com uma lesão pré-maligna, já NIC III. E, às vezes, se acomodam, não } \\
\text { procuram o serviço. E quando chegam aqui, apresenta situação de tratamento inoperável, vai logo pra } \\
\text { radio ou quimioterapia! (Ent. P6). }\end{array}$ \\
\hline
\end{tabular}




\section{Eixo III - Acesso ao tratamento do câncer do colo do útero e ao transporte sanitário}

Nesse nível assistencial, os entrevistados relataram que as mulheres encontravam as maiores dificuldades de acesso ao tratamento do CCU, após a confirmação diagnóstica. Tais problemas centravam-se no acesso ao tratamento propriamente dito (CT-13) e ao transporte sanitário (CT-14).

Foram relatados dificuldades/ausência de comunicação entre profissionais dos serviços de média e alta densidade tecnológica, inexistência de contrarreferência à APS para continuidade do cuidado, desconhecimento do fluxo assistencial por ginecologistas e responsabilização de marcação dos procedimentos pelas próprias usuárias (CT-13).

Os entrevistados destacaram barreiras de acesso relacionadas ao transporte sanitário para mulheres que se deslocavam de seus municípios para a sede da região ou outros centros para tratamento. Na região de saúde, as dificuldades envolviam o desconhecimento dos profissionais quanto ao funcionamento desse serviço, bem como a oferta e a estrutura dos veículos que, muitas vezes, não garantiam o bem-estar e nem a segurança das usuárias em tratamento de câncer. Os gestores, especificamente, ressaltaram a dificuldade para oferta regular do transporte sanitário em decorrência das fragilidades financeiras do próprio município e pela grande demanda de usuários, o que, por consequência, torna um serviço oneroso e de logística complexa para manutenção (CT-14).

Nesse contexto, segundo entrevistados, uma das maiores dificuldades dava-se quando havia necessidade de espera das usuárias durante todo um turno até retornar ao município de origem, agravando-se nos casos de usuárias em vulnerabilidade socioeconômica e/ou com quadro clínico mais grave. A zona rural, mais uma vez, apareceu como fator agravante devido a uma oferta insuficiente de veículos para transporte de usuários, havendo situações em que os mesmos precisam realizar o desembolso direto, quando os carros não estão em estado condizente para a utilização (CT-14).

\section{QUADRO 4}

\section{Acesso ao tratamento do câncer do colo do útero e ao transporte sanitário}

\begin{tabular}{|c|c|}
\hline $\begin{array}{l}\text { Categoria } \\
\text { temática }\end{array}$ & Extratos de falas expressivas \\
\hline \multirow{2}{*}{ 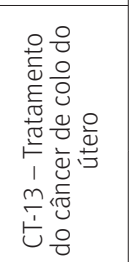 } & $\begin{array}{l}\text { Quando essa paciente vai pra lá (centro de saúde), a gente não tem nenhuma informação dela [...] Até se } \\
\text { a paciente evolui pra algo mais grave do tratamento, a gente acaba não tendo comunicação nenhuma } \\
\text { se ela não vem espontaneamente [à APS]. [...] A gente faz a primeira etapa [referência], mas a segunda } \\
\text { etapa, quando passa pra média e alta [complexidade], eles [profissionais] não dão nenhum retorno! [...] } \\
\text { (GF-IX, Enfermeiros). }\end{array}$ \\
\hline & $\begin{array}{l}\text { [...] parece que a paciente quando recebe o diagnóstico, ela perde a referência da APS! A APS acha que } \\
\text { não é mais responsabilidade dela, porque, às vezes, nem um curativo, uma retirada de ponto, qualquer } \\
\text { coisa que a paciente precise lá no município dela, às vezes, não faz! Tem que vim pra aqui [hospital] pra } \\
\text { poder fazer, porque fala 'ah! É paciente oncológico' e não quer nem mexer! [...] (Ent. G6). }\end{array}$ \\
\hline
\end{tabular}




\begin{tabular}{|c|c|}
\hline $\begin{array}{l}\text { Categoria } \\
\text { temática }\end{array}$ & Extratos de falas expressivas \\
\hline \multirow{5}{*}{ 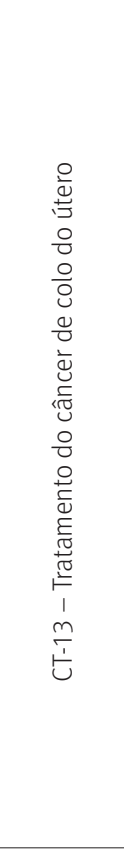 } & $\begin{array}{l}\text { No caso da oncológica [quimioterapia ou radioterapia] ou cirurgia oncológica, [a mulher] não vai } \\
\text { voltar pra mim! Demora, porque vai passar pelo processo cirúrgico, pela revisão cirúrgica! [...] E muitas } \\
\text { pacientes nem vão voltar pra mim! Porque vai ficar no serviço de oncologia muito tempo! Não é igual } \\
\text { ao paciente da biópsia que, obrigatoriamente, vem pra mim! Porque ela não tem outra referência; } \\
\text { a referência sou eu! Mas, depois que sai dessa parte, a referência é outro serviço! O que, às vezes, } \\
\text { acontece é que a paciente vai, faço a biópsia e, aí, às vezes, a paciente não consegue fazer e volta pra } \\
\text { mim, pra dizer que não fez. Mas, se conseguiu o serviço, de modo geral, não voltam! Aí, esse contato, } \\
\text { perco! (Ent. P2, Ginecologista). }\end{array}$ \\
\hline & $\begin{array}{l}\text { Felizmente, ainda, não dá muitas lesões pré-neoplásicas. A gente trata mais processo inflamatório. Se } \\
\text { o procedimento é fazer a CAF [cirurgia de alta frequência], já vai para o município D ou Salvador! Radio, } \\
\text { quimio é, também, em Salvador e município D. [...] Vamos supor que seja uma lesão [de alto grau] } \\
\text { pra um oncologista; explica qual o procedimento e a gente direciona, faz um relatoriozinho (Ent. P3, } \\
\text { Ginecologista). }\end{array}$ \\
\hline & $\begin{array}{l}\text { Algumas alterações, a gente soluciona ou encaminha pro centro de referência. [...]. Quando não resolve } \\
\text { aqui, a gente manda para o centro de referência, como NIC III, que precisa ser cirúrgico, que precisa de } \\
\text { uma conização [...] ou uma histerectomia [...] é encaminhado pra terminar o tratamento numa cidade de } \\
\text { referência. O centro de referência vai encaminhar pra fazer o procedimento ou tratamento [...]. Eu não sei } \\
\text { qual a rotina deles! (Ent. P4, Ginecologista). }\end{array}$ \\
\hline & $\begin{array}{l}\text { A gente regula pra o ginecologista no município D, pra ele falar qual é o tratamento. Abriu agora num } \\
\text { hospital privado [Unacon em hospital privado]. Passou pelo ginecologista, fechou o diagnóstico, aí } \\
\text { vai para a regulação pra poder encaminhar para o município D! No município D, em relação à parte } \\
\text { oncológica, não tem muita dificuldade! Não é } 100 \% \text {, mas flui! A fila anda! (Ent. G3). }\end{array}$ \\
\hline & $\begin{array}{l}\text { O que a gente tem dificuldade, aqui, é com o internamento [pra realizar a cirurgia], porque aqui é um } \\
\text { hospital geral, mas raramente fico impedido de fazer cirurgia por falta de leito. Acontece, eventualmente, } \\
\text { como vaga de UTI [dependendo do caso]. Mas a gente tem dificuldade, sim. Ȧs vezes, consegue vaga } \\
\text { na UTI de última hora. [...] Ãs vezes, vem o pedido pra mim, com a solicitação dos médicos, daqui } \\
\text { ou de outros municípios, mas nem foco nisso. Fico atento aos exames, à história dela. Porque o } \\
\text { encaminhamento não vem com nada da história. Só vem 'consulta oncológica'. [...] Âs vezes, acontece de } \\
\text { paciente chegar sem uma parte dos exames e aí, a gente pede pra retornar pra resolver [...] Mas não tem } \\
\text { esse contato com os outros profissionais (Ent. P6, Ginecologista). }\end{array}$ \\
\hline \multirow{4}{*}{ 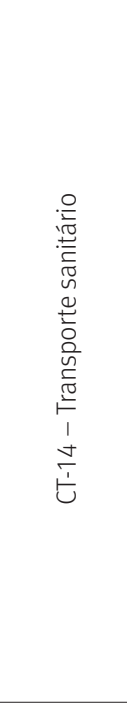 } & $\begin{array}{l}\text { A secretaria oferece o transporte e são até } 15 \text { pessoas por dia! De segunda a quinta! Se for na parte de } \\
\text { quimioterapia, radioterapia, [a secretaria] oferece o carro! [...] No centro de saúde tem a coordenadora } \\
\text { que já marca a paciente. [...] Aî, sempre tá aparecendo paciente [...] Ela sabe a quantidade de paciente } \\
\text { que pode levar [...]. Por exemplo, se ela vai agendar duas ambulâncias [...] a que terminar primeiro com } \\
\text { um paciente, volta. E, a outra, que foi com os pacientes, mais tarde, pega o outro paciente [...]. Aí, por } \\
\text { exemplo, se terminou } 11 \mathrm{~h} \text { e o outro é à tarde, o que chegou por último vai ficar esperando o da tarde! } \\
\text { Tem aqueles horários, com o motorista, já combinado! (Ent. G1). }\end{array}$ \\
\hline & $\begin{array}{l}\text { Nem sempre o município oferece! Tem alguns casos específicos: pacientes que fazem hemodiálise, } \\
\text { tratamento de câncer, quimio, radio. [...] O carro fica disponível até a hora, pra pegar esse paciente. Mas } \\
\text { alimentação não tem não! Quando vai pra Salvador, também, tem esse valor de estadia e alimentação, } \\
\text { mas só para Salvador. Município D, só tem o transporte mesmo! (GF - II, Enfermeiros). }\end{array}$ \\
\hline & $\begin{array}{l}\text { [...] a região de Vitória da Conquista é boa, é tranquila pra trabalhar [...] tô a } 27 \mathrm{~km} \text { [da sede]; é ótimo! Os } \\
\text { meus colegas [gestores] é que sofrem, pra deslocar paciente! [...] A gente que arca com a despesa da } \\
\text { paciente toda! Se tiver condição de ir de ônibus, a gente dá a passagem e ajuda de custo mas se não, o } \\
\text { carro leva! Aí, paga a ajuda de custo mais a diária do motorista; pesa viu?! A gente tem } 92 \text { pacientes de } \\
\text { TFD cadastrados! [...]. Quando é um número maior de pacientes, vai uma van! A gente pega a van que usa } \\
\text { no TFD, ou pega emprestado de alguma secretaria! Tem vezes que o carro vai pra Salvador três vezes na } \\
\text { semana! É um caos! (Ent. G2). }\end{array}$ \\
\hline & $\begin{array}{l}\text { [...] tem uma questão social muito forte, então dependem muito do transporte e dependem do dia que a } \\
\text { prefeitura pode trazer. E acontece do motorista ficar dando pressa, e eles esperando pra consulta. E isso } \\
\text { é, ainda, mais forte na quimio, porque aqui é consulta e é mais rápido [...]. Quando fica dando pressa, } \\
\text { conversa com outros pra passar na frente [...] Mas, na quimio, que demora três horas [...] e eles ficam } \\
\text { apressando [...]. Eles falaram com a gente e marquei uma reunião com o pessoal da ClR; fomos eu e a } \\
\text { enfermeira de lá e pedindo apoio dos gestores pra conversarem com os motoristas [...] é um problema! } \\
\text { (Ent. G6). }\end{array}$ \\
\hline
\end{tabular}




\section{Discussão}

A prevenção e controle do CCU, na APS, dependem, entre outras coisas, da capacidade de profissionais realizarem regularmente exames de Papanicolaou ao conjunto de mulheres na faixa etária preconizada, bem como acompanhar e tratar precocemente todas as usuárias com lesões precursoras detectadas no exame citopatológico (BRASIL, 2013; INCA, 2016a; OPAS, 2016; CANFELL et al., 2020).

Não por acaso, a qualidade do rastreamento tem estreita relação com o processo de trabalho e a competência técnica das equipes envolvidas no exame citopatológico (BARCELOS et al., 2017), valores culturais das mulheres (OSCARSSON; WIJMA; BENZEIN, 2008; NWANKWO et al., 2010; MONTEROS; GALLO, 2011), além dos determinantes socioeconômicos (SONEJI; FUKUI, 2013; TORRES; MIRANDA-RIBEIRO; MACHADO, 2008; ARBYN et al., 2020).

Outrossim, a receptividade/adesão das mulheres (AGUILAR; SOARES, 2015; RICO; IRIART, 2013), os aspectos simbólicos (MONTEROS; GALLO, 2011), questões étnicas (MCLEOD et al., 2010; OLIVEIRA; GUIMARÃES; FRANÇA, 2014), questões de orientação sexual (TRACY; SCHLUTERMAN; GREENBERG, 2013) e de gênero (SOUSA; IRIART, 2018) interferem não apenas na qualidade do rastreamento, mas também na própria realização do rastreamento.

Nessa perspectiva, diferentes sujeitos envolvidos com o controle do CCU, na região estudada, destacaram um melhor desempenho atrelado ao trabalho compartilhado entre médicos e enfermeiros, bem como ações de busca ativa com suporte dos ACS. Além disso, a abrangência das ações clínicas dos enfermeiros estiveram sempre relacionadas à expectativa de maior resolubilidade das alterações percebidas durante exame citopatológico, seja pela competência no tratamento propriamente dito (abordagem sindrômica das IST), seja pela capacidade em realizar encaminhamentos em tempo oportuno (lesões precursoras do CCU), manter a continuidade do cuidado, além de estabelecer relações de proximidade e vínculo com a comunidade.

Não por acaso, fortalecer a conduta clínica dos enfermeiros (VIANA et al., 2013) para que possam ter maior autonomia na abordagem sindrômica e, assim, tratarem outras alterações detectadas durante o exame de Papanicolaou, além de outros agravos crônicos, é uma estratégia de fortalecimento da APS. Na região estudada, os enfermeiros da APS eram o principal profissional para rastreamento do CCU. À vista disso, diferentes sistemas universais têm fortalecido a clínica do enfermeiro, na perspectiva de ampliação do cuidado no âmbito da APS (PERKS; ALGOSO; PETERS, 2017; HÄMEL et al., 2020; KOOIEGA; CARRYER, 2015).

No Brasil, por exemplo, diante da dificuldade de atração e fixação de médicos (GONÇALVES et al., 2019), sobretudo, em municípios pequenos e áreas rurais - justamente aqueles com maior incidência e mortalidade pelo CCU (BARBOSA et al., 2016; SILVA et al. 2011; GOSS et al., 2013) -, o fortalecimento/maior prestígio da clínica desenvolvida por 
enfermeiros precisa ser considerado estratégia para alcance de ações mais abrangentes para controle do CCU.

A perspectiva em foco, todavia, não se traduz em substituição de médicos por enfermeiros ou menor esforço para atração e fixação de médicos nas diferentes regiões do país. 0 debate levantado aponta para um trabalho mais colaborativo entre médicos e enfermeiros, mais resolutivo e alargado em decorrência de maior competência técnica/clínica e utilização de táticas distintas - ampliação do número de enfermeiros por grupos populacionais na APS - por exemplo, para áreas carentes e com população mais vulnerável. Trata-se de estratégia que pode ser utilizada para melhorar o acesso, a eficiência do cuidado e a qualidade de vida (LAURANT et al., 2019).

Entre outras razões, na região em estudo, a participação do médico de APS, dentro da linha de cuidado para controle do CCU, era focada em intervenções terapêuticas, mediante alguma alteração ginecológica percebida por enfermeiros, ou encaminhamentos para outros níveis de atenção. 0 exame citopatológico, as ações comunitárias e o monitoramento dos casos ficavam sob responsabilidade de enfermeiros e ACS, posto que o cerne do trabalho médico permanecia centrado na doença.

Em relação à qualidade dos laudos do exame preventivo, tal problemática apontada por entrevistados poderia estar atrelada a condições e técnicas de coleta do material, fixação inadequada e armazenamento das lâminas, transporte das lâminas ao laboratório ou envolver a leitura das lâminas no laboratório (AMARAL et al., 2008; BORTOLON et al., 2012; INCA, 2016b). As recomendações para garantia de citologia de alto padrão requerem capacitação técnica de médicos e enfermeiros para excelência na coleta, disponibilidade de insumos em quantidade e qualidade suficientes para coleta segura, cadastro eletrônico ou manual dos exames realizados e encaminhados para correto acompanhamento do retorno dos laudos do exame Papanicolaou e estruturação de laboratórios de referência para citopatologia, que, por sua vez, devem seguir as normas técnicas no que tange à produção e capacidade técnica de leitura das lâminas (INCA, 2016a, 2016b; OPAS, 2016; BRASIL, 2013).

Trata-se de aspecto importante para controle do CCU, pois, diante das barreiras de acesso ao preventivo (FERNANDES et al., 2019; GALVÃO et al., 2019) e dos desafios à adesão ao rastreamento (OSCARSSON et al., 2008), causa perplexidade que as mulheres que têm acesso ao primeiro ponto de contato para controle ao CCU possam ter lesões precursoras não tratadas em tempo oportuno por questões organizacionais ou técnicas que comprometem o diagnóstico precoce. Além disso, amostras insatisfatórias, em decorrência de condutas técnicas inadequadas e evitáveis, representam custo aos municípios - uma vez que não há restrição ao pagamento de exames insatisfatórios -, assim como há exposição da mulher que deverá realizar nova coleta, com risco de danos à saúde por atraso nos resultados (BRASIL, 2013; OPAS, 2016).

Em contrapartida, o encaminhamento ao especialista por profissionais da APS, nos casos de LSIL, comum em um dos municípios, indica opção de protocolo dissonante com o indicado pelo Ministério da Saúde. Tal conduta pode estar relacionada à insegurança 
clínica, ao desconhecimento do protocolo ou opção por tratamento intervencionista em detrimento da conduta expectante (GIACCIO et al., 2010). De todo modo, promove referenciamentos desnecessários e maior exposição das mulheres aos exames ginecológicos. Além disso, num contexto de dificuldades para consultas na rede especializada, tal procedimento pode concorrer com casos que, de fato, têm necessidade de consulta/intervenção com ginecologista.

Em relação à continuidade do cuidado (CUNHA; GIOVANELLA, 2011), deve haver disponibilidade diversificada de ações e serviços que permitam a integralidade da atenção necessária ao controle do CCU. Na lógica das redes de atenção, trata-se de sistema de apoio (diagnóstico e terapêutico) e sistema logístico (regulação assistencial, transporte sanitário e tecnologia informacional entre níveis) articulados à APS (coordenação assistencial e gestão clínica) (MENDES, 2010).

Nessa perspectiva, a APS deve funcionar como centro de comunicação na RAS, de modo a coordenar os fluxos e contrafluxos (MENDES, 2010). Por meio do atributo da coordenação (STARFIELD, 2020), os profissionais da APS podem atuar de forma mais resolutiva nas condições crônicas (MENDES, 2012; MENDES; ALMEIDA, 2020), inclusive no controle do CCU (ANJOS, 2020; GALVÃO et al., 2019).

Ademais, a coordenação do cuidado em saúde pela APS contribui para aumentar a satisfação dos usuários, uma vez que possibilita o alcance de uma resposta mais integral e resolutiva (ALMEIDA; GIOVANELLA; NUNAN, 2012). Não obstante, possuir alto nivel de coordenação está associado a ter alto nível de qualidade da assistência à saúde da mulher (CRUZ et al., 2019).

Na região estudada, havia integração frágil para continuidade do cuidado com vistas ao controle do CCU. Constatou-se que ações fundamentais como colposcopia e biópsia retardavam o diagnóstico e, consequentemente, o tratamento delongava-se em detrimento da saúde das mulheres. Tais limites organizacionais implicavam descrédito no SUS e, por conseguinte, a busca por serviços privados para garantia de parte do itinerário assistencial, acarretando iniquidades, uma vez que o CCU é mais incidente entre mulheres mais vulneráveis (BARBOSA et al., 2016; SONEJI; FUKUI, 2013; GOSS et al., 2013).

Um efeito paradoxal da regionalização (ALMEIDA et al., 2016; SANTOS, 2018) dava-se pela necessidade de deslocamento das usuárias para outros municípios quando buscavam, sobretudo, apoio diagnóstico e tratamento. Nesse sentido, ainda que possa responder à lógica de racionalização de escopo e de escala, a não proximidade para resolução de problemas essenciais à confirmação diagnóstica de lesões precursoras provocava atraso no tratamento e peregrinação da usuária na rede, ou mesmo desistência. Nessa direção, ressalta-se que se tratava de mulheres de municípios muito pobres e, comumente, com baixa escolaridade, oriundas, muitas vezes, de zonas rurais e, por conseguinte, com restrições financeiras para arcar com os deslocamentos ou mesmo dificuldades para transitarem no município de referenciamento. 
Tais questões corroboram outras pesquisas em região de saúde para diferentes agravos (FAUSTO et al., 2017; SANTOS et al., 2017). Ademais, estudos apontam, ainda, que indicadores socioeconômicos positivos correlacionam-se inversamente com a mortalidade por CCU e ao longo de 30 anos (1980-2010) houve declínio na mortalidade por CCU, com exceção de municípios do interior do Norte e Nordeste (GIRIANELLI; GAMARRA; SILVA, 2014). Além disso, a dificuldade de acesso a serviços de diagnóstico e tratamento para mulheres residentes fora dos grandes centros urbanos contribui para um desfecho desfavorável (SILVA et al., 2011). Trata-se, desse modo, de uma condição marcadora adequada para avaliação da qualidade da rede de serviços de saúde (BOTTARI; VASCONCELLOS; MENDONÇA, 2008).

A realidade da região de saúde estudada assemelha-se a outras localidades rurais, uma vez que há maior dificuldade de acesso aos serviços de saúde pela população da zona rural, em decorrência do distanciamento geográfico, da escassez de transporte público e da insuficiência de profissionais (SANTOS; SILVA, 2014).

Tal evidência atesta a favor da atenção à saúde regionalizada e do planejamento intermunicipal cooperativo no território regional (SANTOS, 2018), bem como sinaliza a necessidade de apoio efetivo do ente estadual na intermediação entre os gestores municipais, apoio na organização dos serviços ou mesmo provisão/financiamento direto de serviços (ALMEIDA et al., 2019).

Outro aspecto fulcral no estudo foi a incipiência na regulação assistencial, seja devido à escassez da oferta pública de serviços e à ineficiência da articulação da APS com a rede especializada, seja por conta da inadequação em definir prioridades a fim de que os casos fossem avaliados adequadamente. Por conseguinte, havia tempo de espera alongado, diagnóstico e tratamento tardios e, consequentemente, avanço de casos evitáveis. Tais questões geram ônus ao sistema de saúde, insatisfação dos usuários e reforço da imagem desacreditada do SUS (BRITO-SILVA et al., 2014; ALMEIDA et al., 2016; GALVÃO et al., 2019).

Por essa ótica, as barreiras de acesso aos serviços especializados, a existência de filas de espera sem monitoramento, a dificuldade ou a inexistência de comunicação entre os diferentes pontos da rede são evidências de falhas na coordenação do cuidado e na gestão clínica dos casos (ALMEIDA; GIOVANELLA; NUNAN, 2012). Nesse sentido, a posição que a APS, em especial o médico, assume na rede de atenção é relevante para a construção de uma atenção integral, na qual o usuário seja o centro do cuidado, sendo necessária, para tanto, uma articulação assistencial coordenada (VÁZQUEZ et al., 2017; ALLER et al., 2017).

Contrariando a perspectiva do cuidado integral, na região de saúde, ginecologistas e outros profissionais responsáveis pelo tratamento do CCU não tinham domínio sobre o seguimento da linha de cuidado. Por essa lógica organizativa, revela-se uma lacuna importante na garantia da integralidade, com sérios comprometimentos na cura ou redução de danos às mulheres com CCU. Outrossim, os atrasos e equívocos de encaminhamento davam espaço aos atravessamentos clientelistas, geravam ruídos comunicacionais e fragmentavam a atenção. Em síntese, percebeu-se um ciclo de desinformação, no qual profissionais e 
gestores transferiam a responsabilidade para o outro e, inclusive, culpabilizavam a usuária por entraves durante a sua peregrinação por cuidados.

Por fim, o presente estudo buscou analisar a complexidade dos desafios para controle do CCU no interior do Nordeste, por meio da percepção e experiência de trabalhadores da saúde e gestores. Nesse sentido, trata-se do principal limite do artigo, posto que compreender a produção do cuidado em saúde requer considerar, também, os significados das práticas preventivas e terapêuticas do CCU entre as mulheres (RICO; IRIART, 2013).

\section{Considerações finais}

A permanência de mortes por agravos evitáveis, nomeadamente de mulheres pobres do Nordeste, atesta a necessidade premente de reversão dos modelos fragmentados de atenção à saúde, na perspectiva de correção de iniquidades sociais reproduzidas no interior dos sistemas de serviços de saúde. Por outro lado, a modelagem da linha do cuidado para controle do CCU mostra-se tecnicamente adequada, mas requer a superação de falhas em algumas etapas apontadas neste estudo e a sua implementação de forma mais coordenada e integrada entre os serviços de saúde.

A regionalização é uma diretriz importante para redirecionar a governança colaborativa e viabilizar a organização de uma rede intermunicipal de saúde que, por sua vez, possa viabilizar a oferta de diferentes serviços fundamentais à assistência integral à saúde da mulher e, consequentemente, obter maior resolubilidade.

Entretanto, o estudo aponta que, mesmo em cenários cujos serviços de saúde estejam organizados numa perspectiva de oferta pública regional, tal modelização, por si só, é insuficiente para a garantia da produção do cuidado para controle do CCU. As razões são diversas e perpassam as dimensões político-institucionais da gestão, organizativas dos serviços e das práticas na micropolítica do trabalho em saúde que, por conseguinte, conformam uma linha de cuidado repleta de interrupções que contrariam a integralidade da atenção.

Não por acaso, a vulnerabilidade socioeconômica das mulheres desta região implica maior dificuldade de acesso ao exame citopatológico do útero em diferentes pontos na rede de atenção. No que pesem as coberturas amplas de APS, também ocorre a dificuldade de atração e fixação de profissionais - alta rotatividade -, com prejuízo à longitudinalidade do cuidado e ao vínculo com as mulheres. Tal questão impacta na própria construção de trabalho interprofissional e no planejamento das ações que exigem continuidade e envolvimento comunitário.

0 mesmo acontece com serviços secundários e hospitalares, isto porque é justamente nestes cenários com características mais rurais que perduram os vazios assistenciais, sobretudo para garantia diagnóstica e terapêutica diversificada. Não obstante, quando conseguem realizar o preventivo na APS, as mulheres deparam-se com as incertezas na continuidade na linha de controle do CCU. 
Não por acaso, o subfinanciamento do SUS e a defasagem no valor pago aos procedimentos necessários à integralidade assistencial afugentam os prestadores privados que, em contrapartida, por conta do "monopólio" na oferta, impõem valores de mercado sob controle do interesse privado. Dito de outra forma, o Estado não consegue ofertar diretamente os serviços e, contraditoriamente, precisa comprar o serviço por valores majorados. Nessa equação, os municípios historicamente desassistidos (pequenos, rurais e remotos) permanecem num círculo vicioso entre pobreza que gera adoecimentos, inclusive evitáveis, e insuficiência técnico-econômica de oferta de serviços para tratá-los e preveni-los, perdurando ou gerando novos adoecimentos, bem como o agravamento dos problemas já existentes.

O CCU, agravo de curso longo, sinaliza adequadamente tal problemática nos territórios do interior do Brasil. No estudo em foco, as mulheres deparavam-se com a fragmentação sistemática entre os serviços de saúde e, desse modo, eram orientadas a buscar o serviço privado, por desembolso direto, para abreviar alguns percursos, ou, por total insuficiência econômica, precisavam aguardar tempos alongados para terem diagnóstico e/ou tratamento em tempo oportuno. Logo, a morte de mulheres por CCU é o desfecho cruel dessa trama de iniquidades que embaralha as responsabilidades e dificulta, inclusive, identificar a rede de causalidade.

Na região investigada, a teia de problemas socioeconômicos potencializa a dificuldade de adesão ao rastreamento. Por sua vez, a fragilidade da APS com característica seletiva e a rede de serviços com baixa integração expõem as mulheres que aderiram ao rastreamento e as que conseguiram acesso às incertezas de continuidade e resolubilidade do cuidado.

Por fim, os profissionais estão envolvidos de forma ambígua nessa trama de problemas. Não obstante, os profissionais têm dificuldades de resolução diante da estrutura desfavorável, entretanto, também retroalimentam ou reproduzem iniquidades quando atuam com práticas centradas no procedimento, em detrimento do cuidado às mulheres. Dito de forma distinta, o agir em saúde dos profissionais, também, requer um olhar atento às necessidades de mulheres que vivem em territórios vulneráveis e que, por conseguinte, precisam de práticas proativas e imersão no convívio comunitário para reversão das iniquidades possíveis.

\section{Referências}

AGUILAR, R. P.; SOARES, D. A. Papanicolau: perspectivas de usuárias e profissionais da Estratégia de Saúde da Família da cidade de Vitória da Conquista-BA. Physis: Revista de Saúde Coletiva, v. 25, n. 2, p. 359-379, 2015.

ALLER, M. B. et al. Doctors' opinion on the contribution of coordination mechanisms to improving clinical coordination between primary and outpatient secondary care in the Catalan national health system. BMC Health Services Research, v. 17, 2017.

ALMEIDA, P. F.; GIOVANELLA, L.; NUNAN, B. A. Coordenação dos cuidados em saúde pela atenção primária à saúde e suas implicações para a satisfação dos usuários. Saúde em Debate, v. 36, n. 94, p.375-91, 2012. 
ALMEIDA, P. F. et al. Integração assistencial em região de saúde: paradoxo entre necessidades regionais e interesses locais. Saúde e Sociedade, v. 25, n. 2, p. 320-335, 2016.

ALMEIDA, P. F. et al. Redes regionalizadas e garantia de atenção especializada em saúde: a experiência do Ceará, Brasil. Ciência \& Saúde Coletiva, v. 24, n. 12, p. 4527-4540, 2019.

AMARAL, R. G. et al. Influência da adequabilidade da amostra sobre a detecção das lesões precursoras do câncer cervical. Revista Brasileira de Ginecologia e Obstetrícia, v. 30, n. 11, p. 556-560, 2008.

ANJOS, E. F. Avaliação da qualidade das ações de controle do câncer do colo do útero em uma Região de Saúde do Nordeste brasileiro. 2020. Dissertação (Mestrado em Saúde Coletiva) Instituto Multidisciplinar em Saúde, Universidade Federal da Bahia, Vitória da Conquista, 2020.

ARBYN, M. et al. Estimates of incidence and mortality of cervical cancer in 2018: a worldwide analysis. Lancet Glob Health, v. 8, n. 2, p. e191-e203, 2020.

BALDOINO, A. S.; VERAS, R. M. Análise das atividades de integração ensino-serviço desenvolvidas nos cursos de saúde da Universidade Federal da Bahia. Revista da Escola de Enfermagem da USP, v. 50, p. 17-24, 2016.

BARBOSA, I. R. et al. Desigualdades regionais na mortalidade por câncer de colo de útero no Brasil: tendências e projeções até o ano 2030. Ciência \& Saúde Coletiva, v. 21, n. 1, p. 253-262, 2016.

BARCELOS, M. R. B. et al. Qualidade do rastreamento do câncer de colo uterino no Brasil: avaliação externa do PMAQ. Revista de Saúde Pública, v. 51, n. 67, 2017.

BORTOLON, P. C. et al. Avaliação da qualidade dos laboratórios de citopatologia do colo do útero no Brasil. Revista Brasileira de Cancerologia, v. 58, n. 3, p. 435-444, 2012.

BOTTARI, C. M. S.; VASCONCELLOS, M. M.; MENDONÇA, M. H. M. Câncer cérvico-uterino como condição marcadora: uma proposta de avaliação da atenção básica. Cadernos de Saúde Pública, v. 24, Supl 1, p. 111-122, 2008.

BRASIL. Ministério da Saúde. Instituto Sírio-Libanês de Ensino e Pesquisa. Protocolos da Atenção Básica: saúde das mulheres. Brasília: Ministério da Saúde, 2016. Disponível em: http://bvsms. saude.gov.br/bvs/publicacoes/protocolos_atencao_basica_saude_mulheres.pdf. Acesso em: 9 mar. 2019.

BRASIL. Presidência da República. Decreto n. 7508 de 28 de junho de 2011. Regulamenta a Lei n. 8.080, para dispor sobre a organização do SUS, o planejamento da saúde, a assistência à saúde e a articulação interfederativa. Brasília, 2011.

BRASIL. Secretaria de Atenção à Saúde. Departamento de Atenção Básica. Controle dos CCU e da mama. Brasília: Ministério da Saúde, 2013. Disponível em: http://bvsms.saude.gov.br/bvs/ publicacoes/controle_canceres_colo_utero_2013.pdf. Acesso em: 8 dez. 2018.

BRITO-SILVA, K. et al. Integralidade no cuidado ao câncer do colo do útero: avaliação do acesso. Revista de Saúde Pública, v. 48, n. 2, p. 240-248, 2014.

CANFELL, K. et al. Mortality impact of achieving WHO cervical cancer elimination targets: a comparative modelling analysis in 78 low-income and lower-middle-income countries. Lancet, v. 395, p. 591-603, 2020.

COELHO, E. A. C. et al. Integralidade do cuidado à saúde da mulher: limites da prática profissional. Escola Anna Nery, v. 13, n. 1, p.154-160, 2009. 
CRUZ, M. J. B. et al. A coordenação do cuidado na qualidade da assistência à saúde da mulher e da criança no PMAQ. Cadernos de Saúde Pública, v. 35, n. 11e00004019, 2019.

CUNHA, E. M.; GIOVANELLA, L. Longitudinalidade/continuidade do cuidado: identificando dimensões e variáveis para a avaliação da Atenção Primária no contexto do sistema público de saúde brasileiro. Ciência \& Saúde Coletiva, v. 16, Supl. 1, p. 1029-1042, 2011.

FAUSTO, M. C. R. et al. Itinerários terapêuticos de pacientes com acidente vascular encefálico: fragmentação do cuidado em uma rede regionalizada de saúde. Revista Brasileira de Saúde Materno Infantil, v. 17, Supl. 1, p. S63-S72, 2017.

FERNANDES, N. F. S. et al. Acesso ao exame citológico do colo do útero em região de saúde: mulheres invisíveis e corpos vulneráveis. Cadernos de Saúde Pública, v. 35, n. 10, e00234618, 2019.

GALVÃO, J. R. et al. Percursos e obstáculos na Rede de Atenção à Saúde: trajetórias assistenciais de mulheres em região de saúde do Nordeste brasileiro. Cadernos de Saúde Pública, v. 35, n. 12, e00004119, 2019.

GIACCIO, C. M. R. S. et al. Evolução das lesões intraepiteliais de colo uterino de baixo grau em uma coorte de pacientes acompanhadas por 18 meses. Diagnóstico \& Tratamento, v. 15, n. 4, p. 170-173, 2010.

GIOVANELLA, L.; ALMEIDA, P. F. Atenção primária integral e sistemas segmentados de saúde na América do Sul. Cadernos de Saúde Pública, v. 2, Supl. 2, e00118816, 2017.

GIRIANELLI, V. R.; GAMARRA, C. J.; SILVA, G. Os grandes contrastes na mortalidade por câncer do colo uterino e de mama no Brasil. Revista de Saúde Pública, v. 48, n. 3, p. 459-467, 2014.

GONÇALVES, R. F. et al. Influência do Mais Médicos no acesso e na utilização de serviços de saúde no Nordeste. Revista de Saúde Pública, v. 53, n. 110, 2019.

GOSS, P. E. et al. Planning cancer control in Latin America and the Caribbean. Lancet Oncology, v. 14, n. 5, p. 391-436, 2013.

HÄMEL, K. et al. Advanced practice nursing in primary health care in the Spanish National Health System. Ciência \& Saúde Coletiva, v. 25, n. 1, p. 303-314, 2020.

INCA - Instituto Nacional de Câncer. Coordenação de Prevenção e Vigilância. Divisão de Detecção Precoce e Apoio à Organização de Rede. Diretrizes brasileiras para o rastreamento do CCU. 2. ed. Rio de Janeiro: Inca, 2016a.

INCA - Instituto Nacional de Câncer. Coordenação de Prevenção e Vigilância. Divisão de Detecção Precoce e Apoio à Organização de Rede. Manual de gestão da qualidade para laboratório de citopatologia. 2. ed. Rio de Janeiro: Inca, 2016b.

INCA - Instituto Nacional de Câncer. Parâmetros técnicos para o rastreamento do câncer do colo do útero. Rio de Janeiro: Inca, 2019.

KOOIENGA, S. A.; CARRYER, J. B. Globalization and advancing primary health care nurse practitioner practice. The Journal for Nurse Practitioners, v. 11, n. 8, p. 804-811, 2015.

LAURANT, M. et al. Nurses as substitutes for doctors in primary care. Cochrane Database Systematic Reviews. v. 7, 2018.

MAIA, C. S. et al. Percepções sobre qualidade de serviços que atendem à saúde da mulher. Ciência \& Saúde Coletiva, v. 66, n. 5, p. 2567-2574, 2011.

MALTA, D. C.; JORGE, A. O. Análise de tendência de citologia oncótica e mamografia das capitais brasileiras. Ciência e Cultura, v. 66, n. 1, p. 25-29, 2014. 
MCLEOD, M. et al. Improving survival disparities in cervical cancer between Māori and non-Māori women in New Zealand: a national retrospective cohort study. Australian and New Zealand Journal of Public Health, v. 34, n. 2, 2010.

MENDES, E. V. As redes de atenção à saúde. Ciência \& Saúde Coletiva, v. 15, n. 5, p. 2297-305, 2010.

MENDES, E. V. O cuidado das condições crônicas na APS: o imperativo da consolidação da estratégia da saúde da família. Brasília: Opas, 2012.

MENDES, L. S.; ALMEIDA, P. F. Médicos da atenção primária e especializada conhecem e utilizam mecanismos de coordenação? Revista de Saúde Pública, v. 54, n. 121, 2020.

MINAYO, M. C. S. O desafio do conhecimento: pesquisa qualitativa em saúde. 14. ed. São Paulo: Hucitec, 2014.

MONTEROS, K. E.; GALLO, L. C. The relevance of fatalism in the study of Latinas' cancer screening behavior: a systematic review of the literature. International Journal of Behavioral Medicine, v. 18, n. 4, p. 310-318, 2011.

MURAMOTO, F. T.; MATUMOTO, S. Repercusiones del programa brasileño de evaluación de la calidad en la atención primaria en salud repercussions of the Brazilian. Revista Cubana de Enfermería, v. 35, n. 3, p. 1-17, 2019.

NWANKWO, K. C. et al. Knowledge atitudes and practices of cervical cancer screening among urban and rural Nigerian women:a call for education and mass screening. European Journal of Cancer Care, v. 20, n. 3, p. 362-7, 2011.

OLIVEIRA, M. V.; GUIMARÃES, M. D. C.; FRANÇA, E. B. Fatores associados a não realização de Papanicolau em mulheres quilombolas. Ciência \& Saúde Coletiva, v. 19, n. 11, p. 4535-4544, 2014.

OPAS - Organização Pan-Americana da Saúde. Controle integral do câncer do colo do útero. Guia de práticas essenciais. Washington, DC: Opas, 2016.

OSCARSSON, M. G.; WIJMA, B. E.; BENZEIN, E.G. 'I do not need to... I do not want to... I do not give it priority...' - why women choose not to attend cervical cancer screening. Health Expectations, v. 11, n. 1, p. 26-34, 2008.

PERKS, J.; ALGOSO, M.; PETERS, K. Nurse practitioner (NP) led care: cervical screening practices and experiences of women attending a women's health centre. Collegian, v. 25, n. 5, p. $493-$ 499, 2017.

RICO, A. M.; IRIART, J. A. B. "tem mulher, tem preventivo": sentidos das práticas preventivas do câncer do colo do útero entre mulheres de Salvador, Bahia, Brasil. Cadernos de Saúde Pública, v. 29, n. 9, p. 1763-1773, 2013.

SANTOS, A. M. Redes regionalizadas de atenção à saúde: desafios à integração assistencial e à coordenação do cuidado. Salvador: Edufba; 2018.

SANTOS, C. M. D. et al. Avaliação da rede de atenção ao portador de hipertensão arterial: estudo de uma região de saúde. Cadernos de Saúde Pública, v. 33, n. 5, e00052816, 2017.

SANTOS, R. C.; SILVA, M. S. Condições de vida e itinerários terapêuticos de quilombolas de Goiás. Saúde \& Sociedade, v. 23, n. 3, p. 1049-1063, 2014.

SILVA, G. A. et al. Tendência da mortalidade por câncer nas capitais e interior do Brasil entre 1980 e 2006. Revista de Saúde Pública, v. 45, n. 6, p. 1009-1018, 2011.

SONEJI, S.; FUKUI, N. Socioeconomic determinants of cervical cancer screening in Latin America. Revista Panamamericana de Salud Pública, v. 33, n. 3, p. 174-182, 2013. 
SOUSA, D.; IRIART, J. "Viver dignamente": necessidades e demandas de saúde de homens trans em Salvador, Bahia, Brasil. Cadernos de Saúde Pública, v. 34, n. 10, e00036318, 2018.

STARFIELD, B. Atenção primária: equilíbrio entre necessidades de saúde, serviços e tecnologia. Brasília: Unesco/Ministério da Saúde, 2002.

TAYLOR, V. M. et al. Evaluation of a cervical cancer control intervention using lay health workers for Vietnamese American women. American Journal of Public Health, v. 100, n. 10, p. 1924-1929, 2010.

TOMASI, E. et al. Estrutura e processo de trabalho na prevenção do câncer de colo de útero na Atenção Básica à Saúde no Brasil: Programa de Melhoria do Acesso e da Qualidade - PMAQ. Revista Brasileira de Saúde Materno Infantil, v. 15, n. 2, p. 171-180, 2015.

TORRES, M. E. A.; MIRANDA-RIBEIRO, P.; MACHADO, C. J. "Vai lá, tira a roupa... e... pronto...”: o acesso a consultas ginecológicas em Belo Horizonte, MG. Revista Brasileira de Estudos de População, v. 25, n. 1, p. 49-69, 2008.

TRACY, J. K.; SCHLUTERMAN, N. H.; GREENBERG, D. R. Understanding cervical cancer screening among lesbians: a national survey. BMC Public Health, v. 13, n. 442, 2013.

VÁZQUEZ, M. L. et al. Doctors' experience of coordination across care levels and associated factors. A cross-sectional study in public healthcare networks of six Latin American countries. Social Science \& Medicine, v. 182, p. 10-19, 2017.

VIANA M. R. P. et al. Formação do enfermeiro para a prevenção do câncer de colo uterino. Revista Enfermagem UERJ, v. 21, n. 1, p. 624-630, 2013.

\section{Sobre os autores}

Noêmia Fernanda Santos Fernandes é mestre em Saúde Coletiva pela Universidade Federal da Bahia (UFBA).

Patty Fidelis de Almeida é doutora em Saúde Pública pela Escola Nacional de Saúde Pública Sérgio Arouca. Bolsista de Produtividade do CNPq.

Nília Maria de Brito Lima Prado é doutora em Saúde Coletiva pela Universidade Federal da Bahia (UFBA).

Ângela de Oliveira Carneiro é doutora em Saúde Pública pela Escola Nacional de Saúde Pública Sérgio Arouca.

Eduarda Ferreira dos Anjos é mestre em Saúde Coletiva pela Universidade Federal da Bahia (UFBA).

Jamille Amorim Carvalho Paiva é mestre em Saúde Coletiva pela Universidade Federal da Bahia (UFBA).

Adriano Maia dos Santos é doutor em Saúde Pública pela Escola Nacional de Saúde Pública Sérgio Arouca.

\section{Endereço para correspondência}

Noêmia Fernanda Santos Fernandes

Rua Hormindo Barros, 58, Quadra 17, Lote 58, Bairro Candeias

45029-094 - Vitória da Conquista-BA, Brasil 


\author{
Patty Fidelis de Almeida \\ Rua Marquês de Paraná, 303, Anexo do HUAP, Centro \\ 240302-15 - Niterói-RJ, Brasil \\ Nília Maria de Brito Lima Prado \\ Rua Hormindo Barros, 58, Quadra 17, Lote 58, Bairro Candeias \\ 45029-094 - Vitória da Conquista-BA, Brasil \\ Ângela de Oliveira Carneiro \\ Rua José de Sá Maniçoba s/n, Centro \\ 56304-917 - Petrolina-PE, Brasil \\ Eduarda Ferreira dos Anjos \\ Rua Hormindo Barros, 58, Quadra 17, Lote 58, Bairro Candeias \\ 45029-094 - Vitória da Conquista-BA, Brasil \\ Jamille Amorim Carvalho Paiva \\ Rua João Pereira, Bairro São Vicente \\ 45100-000 - Vitória da Conquista-BA, Brasil \\ Adriano Maia dos Santos \\ Rua Hormindo Barros, 58, Quadra 17, Lote 58, Bairro Candeias \\ 45029-094 - Vitória da Conquista-BA, Brasil
}

\begin{abstract}
Challenges for prevention and treatment of cervico-uterine cancer in Northeast Brazil

The article analyzes the articulation between Primary Health Care (PHC) and the different points of care for cervical cancer (CC) control. It is a qualitative study, with data originated in 10 focus groups (70 participants - nurses and community health agents) and 12 semi-structured interviews (6 managers and 6 gynecologists). The results were grouped into three axes: Early detection and control of CC in PHC; Access to diagnostic confirmation; and Access to CC treatment and health transportation. Results showed problems ranging from screening (failures in Pap smear collection and/or in reading slides in the laboratory, low involvement of PHC physicians, lack of coordination of care between levels) to the treatment of CC (barriers to access to specialized services, fragmentation between services, delay in treatment). Encouraging findings include the clinical practice and the nurses' bond with women during the Pap exam as well as high coverage of the exam in PHC. Main recommendations include permanent in-service education to expand nurses' clinical practice and greater involvement of physicians, as well as closer relations between specialists and PHC professionals to enable care coordination.
\end{abstract}

Keywords: Integrality in health. Regional health planning. Health services accessibility. Primary Health Care. Systems integration. Uterine cervical neoplasms.

\title{
Resumen
}

Desafíos para la prevención y el tratamiento del cáncer cervicouterino en el noreste brasileño

Se analiza la articulación entre la Atención Primaria de Salud (APS) y los diferentes puntos de atención para controlar el cáncer de cuello uterino (CCU). Se trata de un estudio cualitativo con datos de diez grupos focales (setenta participantes - enfermeras y agentes comunitarios- y 
doce entrevistas semiestructuradas a seis gestores y seis ginecólogos). Los resultados se agruparon en tres ejes: 1) detección precoz y control de CCU en la APS; 2) acceso a la confirmación diagnóstica, y 3) acceso al tratamiento del CCU y transporte sanitario e indicaron problemas que van desde el rastreo (fallos en la recolección del Papanicolaou o en la lectura de láminas en el laboratorio, poco involucramiento de los médicos de la APS, falta de coordinación entre niveles) hasta el tratamiento del CCU (barreras para el acceso a los servicios especializados, fragmentación entre servicios, retrasos en el tratamiento). Como resultados alentadores se destacaron la práctica clínica y el vínculo del personal de enfermería con las mujeres durante el Papanicolaou y la alta cobertura del examen en la APS. Como recomendaciones, se debe garantizar la formación permanente en servicio para ampliar la práctica clínica del personal de enfermería y aumentar la participación de médicos, así como una relación más estrecha entre especialistas y profesionales de la APS que permita la coordinación de los cuidados.

Palabras clave: Integralidad en salud. Regionalización. Acceso a servicios de salud. Atención Primaria de Salud. Integración de sistemas. Neoplasias del cuello uterino.

Recebido para publicação em 22/04/2020

Aceito para publicação em 06/04/2021 